\title{
PATRONES DE CRECIMIENTO URBANO EN LA METROPOLIZACIÓN DE SISTEMAS URBANOS INTERMEDIOS. EL CASO DE LA CONURBACIÓN LA SERENA - COQUIMBO
}

\section{PATTERNS OF URBAN GROWTH IN THE METROPOLIZATION OF INTERMEDIATE URBAN SYSTEMS, THE CASE OF LA SERENA - COQUIMBO CONURBATION}

\author{
AGUIRRE N., Carlos \\ Universidad de Las Américas \\ Facultad de Arquitectura Diseño y Construcción, Escuela de Construcción \\ Director de Escuela, Profesor Asociado \\ Manuel Montt 948, Santiago, Chile \\ Correo electrónico: caguirre@udla.cl \\ Teléfono: +56 224275171
}

\section{OLIVARES, Rodrigo}

Universidad de La Serena

Facultad de Ingeniería, Escuela de Ingeniería en Construcción

Director de Escuela, Profesor Asistente

Benavente 980, La Serena, Chile.

Correo electrónico: rolivares@userena.cl

Teléfono: +56512204220

\section{ORELLANA M.; Alejandro \\ Universidad de La Serena \\ Departamento de Arquitectura \\ Académico, Profesor Asistente \\ Benavente 980, La Serena, Chile \\ Correo electrónico: aorellana@userena.cl \\ Teléfono: +56 512204454}

Palabras Clave: Crecimiento de ciudades intermedias; fragmentación; análisis espacial

Key words: Growth of intermediate cities; fragmentation; spatial analysis

\section{Resumen}

La conurbación de La Serena- Coquimbo constituye un sistema urbano de ciudades intermedias, localizado en el centro norte de la República de Chile. Con 448.784 habitantes (INE, 2017), ha presentado un sostenido aumento de población y superficie de su mancha urbana en las últimas tres décadas, encaminándose a ser declarada la cuarta área metropolitana del país. Sin embargo, la ciudad enfrenta importantes desafíos en su conformación como sistema metropolitano. La geomorfología de su emplazamiento presenta barreras naturales al desarrollo urbano y una alta vulnerabilidad ante tsunamis; el dinamismo inmobiliario y la fuerte fluctuación de población flotante de carácter estacional contrastan con un sistema vial restringido, acotado geográficamente y en la actualidad ineficiente y una planificación fragmentada.

Citación: AGURRE N., C. et al. Patrones de crecimiento urbano en la metropolización de sistemas urbanos intermedios. El caso de la conurbación La Serena - Coquimbo. En: Libro de proceedings, CTV 2018. XII Congreso Internacional Ciudad y Territorio Virtual. "Ciudades y Territorios Inteligentes". UNCuyo, Mendoza, 5-7 septiembre 2018. Barcelona: CPSV, 2018, p. $77-96$ 
En este contexto, este estudio busca develar la lógica espacial de las formas de crecimiento de la conurbación, caracterizando tipologías de proyectos y oferta inmobiliaria, y, a partir de un modelo de ciudad en expansión y crecimiento de baja densidad a media densidad, relacionarla con los problemas actuales de la conurbación.

Con un enfoque cuantitativo, se hace el análisis espacial de datos censales, de permisos de edificación, y de fotos satelitales, obteniendo como resultados, tanto los patrones de crecimiento como las tendencias de edificación.

Las conclusiones apuntan a la identificación de polos de crecimiento de la conurbación que están incorporando nuevas dinámicas espaciales de concentración de población y tipologías edificatorias aglomeradas espacialmente. En segundo lugar, una disminución de la fragmentación espacial en el espacio de conurbación a medida que se rellenan los espacios no edificados. Por último, un cambio de la pendiente de los crecimientos en extensión (viviendas unifamiliares) y densidad (viviendas plurifamiliares).

\section{Abstract}

The conurbation of La Serena-Coquimbo is an urban system of intermediate cities, located in the northern center of Chile. With 448,784 inhabitants (INE, 2017), it has presented a sustained increase in population and area of its urban sprawl in the last three decades, in the way of being the fourth largest metropolitan area in the country. However, the city faces significant challenges in its conformation as a metropolitan system. The geomorphology of its site presents natural barriers to urban development and a high vulnerability to tsunamis; the dynamism of real estate and the strong fluctuation of floating seasonal population contrast with an inefficient road system and a fragmented planning.

In this context, this study seeks to unveil the spatial logic of the forms of growth of the conurbation, characterizing project typologies, and, from a model of expanding city and lowdensity growth to medium density, relate it to current problems of the conurbation.

With a quantitative approach, the spatial analysis of census data, building permits, and satellite photos is made, obtaining as results, both growth patterns and building trends.

The conclusions point to the identification of poles of growth in the conurbation that are incorporating new spatial dynamics of population concentration and spatially agglomerated building typologies. Second, a decrease in spatial fragmentation in the conurbation space as unbuilt spaces is filled. Finally, is detected a change in the slope of growth in extension (singlefamily dwellings) and density (multi-family dwellings).

\section{Introducción}

La rápida expansión de las ciudades latinoamericanas y, por lo tanto, el crecimiento subsiguiente de las áreas urbanas ha llevado a procesos de metropolización entre núcleos urbanos aledaños. Esta expansión se explica por la dependencia económica a lo largo de la historia de las economías nacionales, a través de una serie de etapas que vienen desde su

Citación: AGURRE N., C. et al. Patrones de crecimiento urbano en la metropolización de sistemas urbanos intermedios. El caso de la conurbación La Serena - Coquimbo. En: Libro de proceedings, CTV 2018. XII Congreso Internacional Ciudad y Territorio Virtual. "Ciudades y Territorios Inteligentes". UNCuyo, Mendoza, 5-7 septiembre 2018. Barcelona: CPSV, 2018, p. 77-96. 
inicio vinculadas a su funcionamiento como enclaves dependientes entre distintos territorios, permitiendo el contacto y el intercambio económico entre ellos.

En un segundo período de crecimiento se explica por la necesidad de responder a la situación internacional, en la que el modelo económico se caracteriza por dar énfasis a la producción local, lo que lleva a la política de sustitución de importaciones. Así, nacieron industrias nacionales, aumentaron los servicios, el trabajo y, por ende, el escenario de las ciudades, resultado del aumento de la migración rural-urbana, concentrando a la población en redes urbanas que estaban dando origen a diferentes agrupaciones de crecimiento endógeno.

La reapertura de la economía internacional es la tercera etapa en la que las áreas metropolitanas responden y ofrecen mejores condiciones para la producción y el intercambio con otros centros económicos, ya que tienen similitudes en su desarrollo y estructura. En esta etapa se enfatiza la centralización, donde todas las actividades convergen en estas áreas. Un ejemplo es la integración social global conjunta y el desarrollo territorial del modelo establecido por la aglomeración de Buenos Aires, Rosario y Córdoba La Plata en Argentina. La transformación económica y la concentración producto de la globalización, ha llevado a cambios en la configuración espacial de las ciudades, conduciendo a la segregación y fragmentación, términos socioeconómicos y administrativos, creando desigualdades en la calidad de los servicios públicos en el equipamiento de las ciudades y desencadenando nuevos procesos territoriales, entendido no solo como el desbordamiento de límites administrativos.

Los procesos económicos han sido influyentes en el desarrollo de las ciudades y el tipo de crecimiento que han tenido históricamente. Las décadas recientes, debido al proceso de globalización, han llevado al crecimiento y la transformación de las grandes ciudades, convirtiéndose en centros urbanos y económicos para sus países y la región, lo que resulta en la reestructuración y funcionalización de las ciudades. En este contexto, los patrones de ocupación de la tierra debido a la movilidad, los agentes urbanos y la organización de términos productivos basados en el sistema de clústeres y que involucra a los centros urbanos cercanos. Las ciudades de la región y las áreas metropolitanas son la plataforma donde surgen nuevas estrategias de consumo y producción, representadas por centros comerciales, autopistas urbanas o comunidades cerradas. Tienen en común el rápido crecimiento y la urbanización que han experimentado, superando la velocidad con que se hacen las estrategias para planificar el territorio. Dando lugar a problemas urbanos como la fragmentación y la segregación territorial. La urbanización en Chile, ha sido producto, en primer lugar, del desarrollo y explotación de los recursos naturales, en cuyos entornos se han generado asentamientos humanos, determinando la ubicación de las ciudades y, por otro lado, por las diferentes formas de organización de la economía (Hidalgo, De Mattos, Arenas, 2009).

En el contexto de la globalización, las ciudades chilenas han asumido diferentes estructuras, donde la dispersión de los edificios en el área ha ido creciendo, superando los centros de concentración y dando paso a la ocupación de la periferia, estructurando una nueva geografía con el crecimiento de la expansión urbana abarca los territorios cercanos, incrementando sus límites para ocupar áreas rurales que inicialmente serán para llevar a cabo la expansión de los límites de la ciudad y ser parte de nuevas áreas y tendencias demográficas. Según esto y considerando los datos del Instituto Nacional de Estadística (INE), la población urbana nacional está distribuida en 248 ciudades. Algunas reuniones conformadas por un conjunto de espacios con un límite urbano independiente, unidos entre sí por los sistemas de transporte público frecuentes, que constituyen una unidad única desde el punto de vista funcional, originaron 27 ciudades en agrupaciones (MINVU).

Citación: AGURRE N., C. et al. Patrones de crecimiento urbano en la metropolización de sistemas urbanos intermedios. El caso de la conurbación La Serena - Coquimbo. En: Libro de proceedings, CTV 2018. XII Congreso Internacional Ciudad y Territorio Virtual. "Ciudades y Territorios Inteligentes". UNCuyo, Mendoza, 5-7 septiembre 2018. Barcelona: CPSV, 2018, p. 77-96. 
De acuerdo con la lista oficial de ciudades en 2007, el INE define tres áreas metropolitanas en Chile, de norte a sur: el Área Metropolitana de Valparaíso y Metropolitana de Valparaíso (AMV), Área Metropolitana de Santiago o Área Metropolitana de Santiago (AMS) y Área Metropolitana Concepción o Metropolitano, el más grande en términos de población y área de la MGA con 5.638.820 habitantes (censo de población de 2002) y que tiene entre sus componentes la capital. Las áreas metropolitanas se caracterizan por la interacción económica y social de diferentes unidades territoriales, áreas o centros inmediatos, más allá de la planificación, que se extienden a áreas cercanas cuyos límites son las acciones que se ejercen entre sí dentro de una línea imaginaria.

En términos oficiales, el Urbanismo General y la Construcción (OGUC) definieron como área urbana la "área de terreno ubicada dentro de los límites de la ciudad, para el desarrollo armonioso de los centros de población y las actividades existentes y proyectada por el instrumento de planificación territorial" de esa manera y dentro de la planificación urbana, la unidad cuando supera los 500,000, va a la categoría de área metropolitana para fines de planificación. Es decir, cuando hay un desbordamiento de límites administrativos, tanto en la población como en los territorios, se producen fenómenos como la aglomeración o conurbación, entendidos como un "Conjunto de varios centros urbanos inicialmente independientes y contiguos a lo largo de sus orillas, que crecen eventualmente como una unidad funcional. "(Real Academia de la Lengua Española) y son las que conducen a la formación de un área metropolitana. En este caso, las áreas metropolitanas son el área metropolitana de Santiago, el gran Valparaíso y la gran Concepción.

\section{La conurbación La Serena - Coquimbo}

\subsection{Características}

La región de Coquimbo (IV), capital La Serena, tiene una superficie de 40.509,9 kilómetros cuadrados, equivalente al $5,4 \%$ del territorio nacional (descontando territorio antártico). Se localiza en la sección meridional del extremo norte del país, tradicionalmente conocido como "Norte Chico". Se caracteriza por tener el ancho mínimo del territorio chileno con $90 \mathrm{Km}$, entre el paso de la Casa de Piedra y Punta Amolanas, a la altura de Illapel. Cifras del Censo 2017 indican que la población alcanza los 757.586 habitantes (368.774 hombres y 388.812 mujeres). En relación al clima, este corresponde a uno semiárido, lo que permite una variada vegetación.

Figura 1. Localización de la conurbación

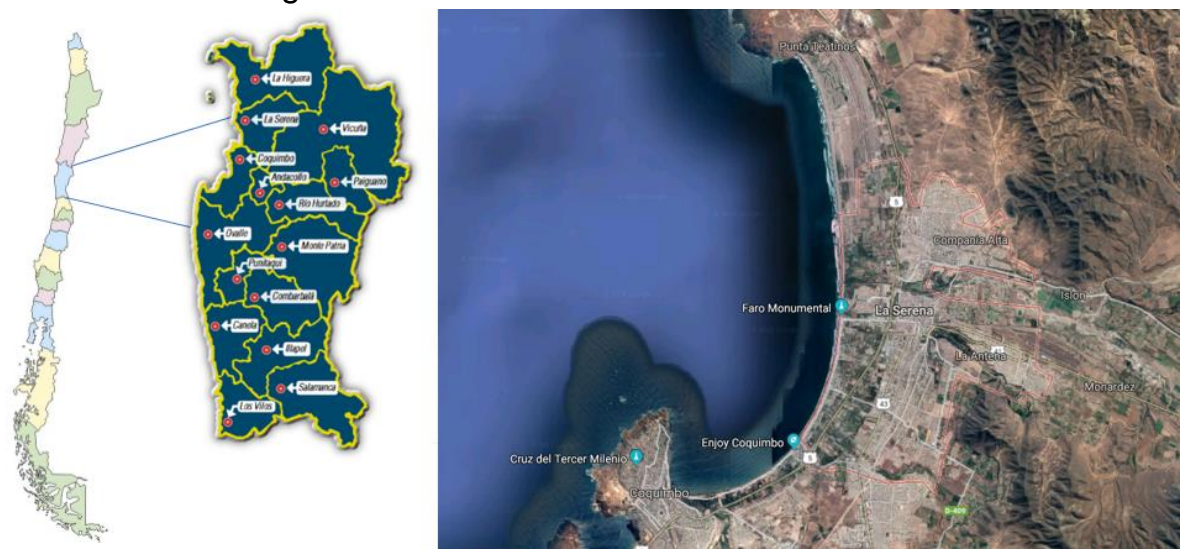

Fuente: Elaboración propia, en base a Atlas Geográfico de Chile

Citación: AGURRE N., C. et al. Patrones de crecimiento urbano en la metropolización de sistemas urbanos intermedios. El caso de la conurbación La Serena - Coquimbo. En: Libro de proceedings, CTV 2018. XII Congreso Internacional Ciudad y Territorio Virtual. "Ciudades y Territorios Inteligentes". UNCuyo, Mendoza, 5-7 septiembre 2018. Barcelona: CPSV, 2018, p. 77-96. 
Tabla 1. Datos demográficos de la Conurbación

\begin{tabular}{|c|c|c|c|c|c|c|}
\hline Superficie (Km2) & $\begin{array}{c}\text { \% en la } \\
\text { superficie } \\
\text { nacional* }\end{array}$ & Población (hab) & $\begin{array}{c}\text { \% en la } \\
\text { población } \\
\text { nacional }\end{array}$ & $\begin{array}{c}\text { Densidad } \\
\text { (hab/km2) }\end{array}$ & $\begin{array}{c}\text { Mujeres/Hombres } \\
\text { (\%) }\end{array}$ & $\begin{array}{l}\text { Ruralidad } \\
2014(\%)\end{array}$ \\
\hline $40.579,9$ & 5,4 & 757.586 & 4,3 & 18,7 & $\begin{array}{l}51,3 \\
48,7\end{array}$ & 19,2 \\
\hline
\end{tabular}

Fuente: Instituto Nacional de Estadísticas INE, 2017

Del total de población, $81,2 \%$ vive en el área urbana y $18,8 \%$ lo hace en el área rural, en contraste con los resultados a nivel nacional, donde los porcentajes llegan a $87,8 \%$ y $12,2 \%$, respectivamente. La Región de Coquimbo es la que concentra mayor ruralidad en la zona Norte del país.

Según cifras del Censo 2017, la rama de actividad económica en que se ocupa la población de 15 años o más que al momento del censo declaró haber trabajado. Así, el 77\% se desempeña en el sector terciario (comercio; hoteles y restaurantes; transporte, almacenamiento y comunicaciones; intermediación financiera; actividades inmobiliarias, empresariales y de alquiler; administración pública y defensa; enseñanza; servicios sociales y de salud; entre otros), un $18 \%$ trabaja en el sector primario (agricultura, ganadería, caza y silvicultura; pesca, y explotación de minas y cantera) y un $5 \%$, en el sector secundario (industria manufacturera; suministro de electricidad, gas y agua, y construcción).

La estadística de migraciones (según extranjería), ${ }^{1}$ registradas desde 2005 al 2016 de la Región de Coquimbo.

- Se registran 5.371 Permanencias Definitivas otorgadas entre los años 2005 al 2016 a nivel regional, con un $74,93 \%$ de permanencias localizadas entre las comunas de La Serena y Coquimbo; un 10,22 \% de permanencias definitivas en la Comuna de Ovalle y el $14,83 \%$ restante en el resto de las comunas.

- Y en la región se registran entre los años 2011 al 2016, 17.269 Visas temporales y sujetas a contrato de trabajo, entre las comunas de La Serena (6.276) y Coquimbo (5.811), conteniendo $70 \%$ de visas sólo en la Conurbación en la región.

La conurbación denominada "La Serena-Coquimbo "es una de los principales conglomerados de ciudades en Chile, está constituida por 448.784 habitantes (CENSO 2017), y con una superficie urbana de 6.238 hectáreas, la cuarta entidad urbana del país. Está localizada en la IV Región, y tiene múltiples atractivos turísticos, que la convierten en uno de los destinos preferidos en verano tanto para nacionales como extranjeros.

También son ciudades con un alto número de migrantes que llegan a ella como lugar de retiro y descanso post-jubilación. En la última década, la instalación de importantes empresas mineras en la Región de Atacama y de Antofagasta, ha potenciado también su vocación residencial, gracias a su relativa cercanía al centro del país, específicamente a Santiago, y la oferta de servicios que posee (salud, educación universitaria, entre otros). Aunque ha ocupado un rol como productor y distribuidor de productos agrícolas desde y hacia el sur, tiene hoy el desafío de ser la ciudad y puerto de salida de las exportaciones que vienen desde Argentina y Brasil, a través del "Proyecto Corredor Bioceánico Paso Fronterizo Aguas Negras".

\footnotetext{
${ }^{1}$ http://www.extranjeria.gob.cl/estadisticas-migratorias/
}

Citación: AGURRE N., C. et al. Patrones de crecimiento urbano en la metropolización de sistemas urbanos intermedios. El caso de la conurbación La Serena - Coquimbo. En: Libro de proceedings, CTV 2018. XII Congreso Internacional Ciudad y Territorio Virtual. "Ciudades y Territorios Inteligentes". UNCuyo, Mendoza, 5-7 septiembre 2018. Barcelona: CPSV, 2018, p. 77-96. 
La conurbación Serena-Coquimbo resulta ser un caso de estudio de gran interés, aun mas haciendo revisión de las historia de la ciudad de La Serena, es muy importante destacar de lo realizado en el denominado "Plan Serena" (1949), que concretó una visión de ciudad y ejecutó las obras necesarias para lograrla, junto con establecer una normativa y el consenso de la ciudad que ha permitido la conservación de su estilo.

\subsection{Plan Serena}

El Plan de Fomento y Urbanización para las Provincias de Chile, constituyó un plan de acciones concertadas por parte del Estado de Chile, tendiente a producir una descentralización territorial, generar una base económica propia, y transformar el hábitat, a través de una planificación centralizada, y que tomo a la ciudad de La Serena como su plan piloto. El presidente de la época Don Gabriel González Videla resultó clave en la concepción del aparato de gestión y desarrollo del plan. A nivel regional propuso como objetivos el desarrollo de la provincia de Coquimbo; comprendió acciones sobre los aspectos de la agricultura, la minería, el turismo, la educación, la colonización, la infraestructura vial, energía y servicios. La importancia del Plan en el contexto de la evolución de la planificación en Chile, surge claramente por su sentido, su operación y sus resultados.

El Plan consagra históricamente la intervención y el papel del estado en la estructuración del territorio y la ciudad. Desde el punto de vista disciplinar, el Plan Serena, resulta avanzado en sus premisas, sienta los principios de correspondencia entre planificación territorial y urbana, establece métodos de crecimiento por expansión y de reforma estructural al interior de la planta urbana que no habían surgido antes, y asigna a la arquitectura un rol clave en la configuración de la ciudad. Este plan, desarrollado en Chile, entre 1947 y 1952, aglutinó diferentes escalas de actuación: - desde la territorial, en tanto abarcó la totalidad de una provincia -la de Coquimbo, una de las doce regiones en que hoy se divide el país, - la ínter comunal, planteando obras de infraestructura y recuperación ambiental en la zona de la bahía de Coquimbo, determinando zonas urbanas, separando la industria y proponiendo formad de urbanidad para el turismo, y acciones concertadas entre las dos ciudades del 'área: La Serena y Coquimbo, - la escala de la arquitectura urbana, definiendo las relaciones entre la construcción de la escena urbana y cada edificio, - hasta la escala arquitectónica misma, definiendo los rasgos de la edificación en alturas coherentes y con caracteres estilísticos particulares.

Las obras no sólo se realizaron en la ciudad, sino que se extendieron con rasgos formales similares sobre el territorio de la Provincia. Así por ejemplo, obras como las Termas de Socos, la Escuela Mixta de Salamanca, o las hosterías que llegaron a construirse tanto en el valle interior como en el litoral. Una condición propia del plan que fue la de otorgar a la ciudad una identificación y homogeneidad basada en el estilo. La arquitectura anterior de La Serena era una constitución patrimonial de gran calidad, basada en tipos de casas de patios, con fachadas continuas, de un piso, vanos y grandes puertas. El estado de la edificación era juzgado como deficiente y gran parte de la ciudad se había construido posteriormente al período colonial de una manera aleatoria. La construcción de rasgos de homogeneidad, determinó un nuevo estado de la ciudad. A la vez, una serie de operaciones menores sobre la trama urbana cualificó el ambiente urbano. La construcción de las plazuelas, que habían existido desde la colonia, la apertura de otras, y la reutilización del modelo para la construcción de nuevas áreas de vivienda, fueron un tema reiterado en la construcción de este nuevo estado. Asimismo, se confinó a la planta urbana del centro histórico por un sistema de parques en tres de sus lados,

Citación: AGURRE N., C. et al. Patrones de crecimiento urbano en la metropolización de sistemas urbanos intermedios. El caso de la conurbación La Serena - Coquimbo. En: Libro de proceedings, CTV 2018. XII Congreso Internacional Ciudad y Territorio Virtual. "Ciudades y Territorios Inteligentes". UNCuyo, Mendoza, 5-7 septiembre 2018. Barcelona: CPSV, 2018, p. 77-96. 
lo que la defendía del proceso de desertificación en que ha estado sumido el territorio desde La Serena y su arquitectura patrimonial resultante del ambicioso Plan Serena.

Este plan Serena cuenta con un elemento estructurante y que se ha mantenido en el tiempo, mediante un plan regulador comunal muy restrictivo con las alturas y usos de suelo, y que ha dado forma a esta comuna, mediante desbordes al plan más que en el cumplimiento de este. Asimismo, el proceso de conurbación con Coquimbo, rodeando zonas agrícolas establecidas en ese plan y la sucesiva población de los sectores de Las Compañías, al norte, con vivienda social en extensión principalmente y La Florida, mediante una ficción jurídica de parcelas con viviendas y casas de clase media alta, genera una conurbación con muchos problemas de congestión, y asimismo con una segregación aun mayor que las diferentes ciudades chilenas.

\subsubsection{Problemáticas}

Las comunas de Coquimbo y La Serena, han ido desarrollado sus planificaciones urbanas por sí solas, cuyo resultado ha sido la una mala integralidad de la acción pública en la conurbación para enfrentar situaciones comunes. La inexistencia de políticas multisectoriales para la conurbación no ha permitido un desarrollo integral para ambas ciudades. Un plan de ampliación del puerto también implicaría una mayor presión al sistema vehicular y de transportes y los Caminos que conectan Coquimbo y la Serena podrían quedarían totalmente colapsados en ciertos horarios punta. La demora para ajustar los tiempos de desarrollo y construcción en los proyectos en la ciudad, se traduce en proyectos urbanos y viales que no se llevan a cabo o están obsoletos a la hora de construcción. Duplicidad de acciones entre Vialidad y el MINVU, falta de coordinación entre ambos organismos. Aumento de tomas de terrenos, debido al aumento de los precios de arriendo y a la estacionalidad (aumento de precios en verano) de los mimos. Lo cual es más evidente en Coquimbo, debido a que se ha transformado en una acción válida para el acceso a viviendas, se plantea que Coquimbo se ha urbanizado en función de las tomas.

La construcción de nuevas calles y la extensión de la actual carretera por la futura transformación del puerto, sumado a la construcción del 'corredor bi-oceánico' en el paso Aguas Negras, repercutiría en los barrios y poblaciones de la ciudad de Coquimbo. Mala planificación del transporte urbano, debido al auge de los taxis colectivos en desmedro de los medios de transporte más masivos. El sistema de taxis colectivos no tiene ningún tipo de control en su frecuencia, lo que provoca una ausencia de transporte en diversos horarios. El transporte público y la movilización en la conurbación es una tensión constante, se percibe como un problema que radica en la ineficiencia del sistema, a partir de la inexistencia de sistemas combinados. La deficiencia del sistema de transporte público estaría incentivando el uso del auto particular lo que recrudece el problema del aumento del parque automotriz generando otras problemáticas como el colapso de las vías. Las vías de conexión entre los sectores periféricos y el centro están siendo insuficientes dada la alta densidad de población que reside en ellos quienes se tienen que movilizar cotidianamente hacia el centro donde se encuentran los servicios. En este nudo critico también se incorpora la desigualdad en relación al acceso y a los costos de movilizarse, ya sea en términos económicos, de tiempo y de calidad, para los residentes de la periferia, mala integración de ciclovías, construidas en tramos cortos y en el caso de la Av. Del Mar que tiene una ciclovía en su extensión, no se pueda acceder a ella de manera continua.

Respecto de la Segregación socio-espacial se percibe un aumento, produciéndose una intensificación de las fronteras urbanas; la coexistencia de barrios buenos y barrios malos. Lo

Citación: AGURRE N., C. et al. Patrones de crecimiento urbano en la metropolización de sistemas urbanos intermedios. El caso de la conurbación La Serena - Coquimbo. En: Libro de proceedings, CTV 2018. XII Congreso Internacional Ciudad y Territorio Virtual. "Ciudades y Territorios Inteligentes". UNCuyo, Mendoza, 5-7 septiembre 2018. Barcelona: CPSV, 2018, p. 77-96. 
anterior debido al aumento de construcciones y proyectos inmobiliarios en La Serena. Existe una segregación y estigmatización muy fuerte en el sector de Las Compañías y de Tierras Blancas. Además, se encuentran ubicadas en dos sectores que los separan del resto de la ciudad por elementos geográficos, ha habido poca inversión de conectividad con estos sectores. Existiría una clara diferenciación en el aspecto identitario entre los habitantes de Coquimbo y La Serena, a partir de una identificación de un "otro" distinto.

Respecto de la infraestructura de evacuación son escasas las vías en el contexto de catástrofes naturales (tsunamis), ya que sólo existen dos (Av. Francisco de Aguirre y Av. Cuatro Esquinas) esto sólo dificulta la evacuación. Escasez de las vías de evacuación peatonal en contexto de Tsunamis para la población que se encuentra en los sectores de riesgo de inundación, entre ellos se mencionan la Caleta Los Pescadores en el sector de Peñuelas en Coquimbo y la Caleta San Pedro en La Serena. 5. Falta y mala distribución de equipamiento urbano Baja calidad y cantidad de la infraestructura de salud, insuficiencia de especialidades, provocando que quienes tengan los medios puedan tratarse en Santiago. Siendo éste un problema que es transversal, tanto en el sector público como en el privado. Colapsos vehiculares que se producen en los meses de verano que han estado sujetos a la historia de ambas ciudades y su planificación urbana y vial. La ubicación de los principales servicios públicos se encuentra en el centro de La Serena, sumando las dificultades de movilización hacia el mismo centro, esta concentración de los servicios públicos sería una problemática cotidiana. Se hace referencia a la falta de áreas verdes en Coquimbo en la cual existiría una falta en relación a la densidad de población y en La Serena existiría el problema de la poca cercanía de los parques respecto a las poblaciones en algunos sectores como Las Compañías. Adicionalmente, el crecimiento sostenido de la industria inmobiliaria, ha llevado a la destrucción de las áreas verdes con que cuenta la ciudad, dejando cada vez menos lugares para la creación de parques y plazas. El aumento de la población en Las Compañías provoca la falta de servicios sociales: El significativo crecimiento de la población en La Serena, no ha estado a la par del aumento de los servicios sociales, lo que ha generado una insuficiencia del equipamiento para las poblaciones más alejadas de los lugares en donde se prestan los múltiples servicios sociales.

Este crecimiento está acotado principalmente por los accidentes geográficos, propios de una plataforma litoral y por ende un acotado espacio en diferentes terrazas fluvio-marinas (figura 2 y 3). En ese sentido, acorde al modelo previsto, se puede establecer la necesidad de contar con un nuevo análisis de los crecimientos urbanos y que permita pensar el sistema integrado entre las comunas que componen la conurbación y como estas se relacionan con los otros centros comunales de la provincia y región. En esta investigación, se consideran los patrones de crecimiento urbano de la conrurbación considerada como una sola unidad.

\section{Figura 2. Localización de la conurbación}

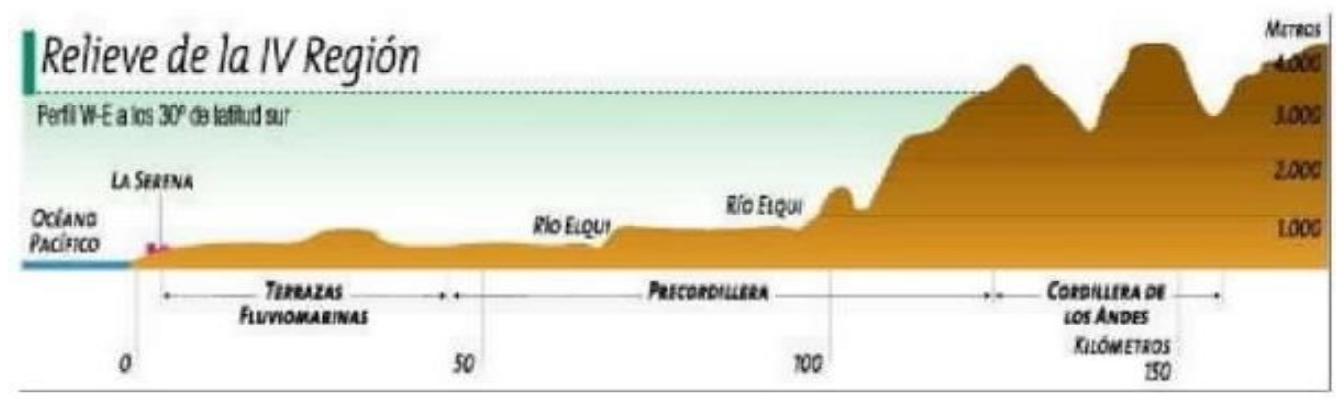

Fuente: Atlas geográfico

Citación: AGURRE N., C. et al. Patrones de crecimiento urbano en la metropolización de sistemas urbanos intermedios. El caso de la conurbación La Serena - Coquimbo. En: Libro de proceedings, CTV 2018. XII Congreso Internacional Ciudad y Territorio Virtual. "Ciudades y Territorios Inteligentes". UNCuyo, Mendoza, 5-7 septiembre 2018. Barcelona: CPSV, 2018, p. 77-96. 
Figura 3. Disponibilidad de suelos urbanos

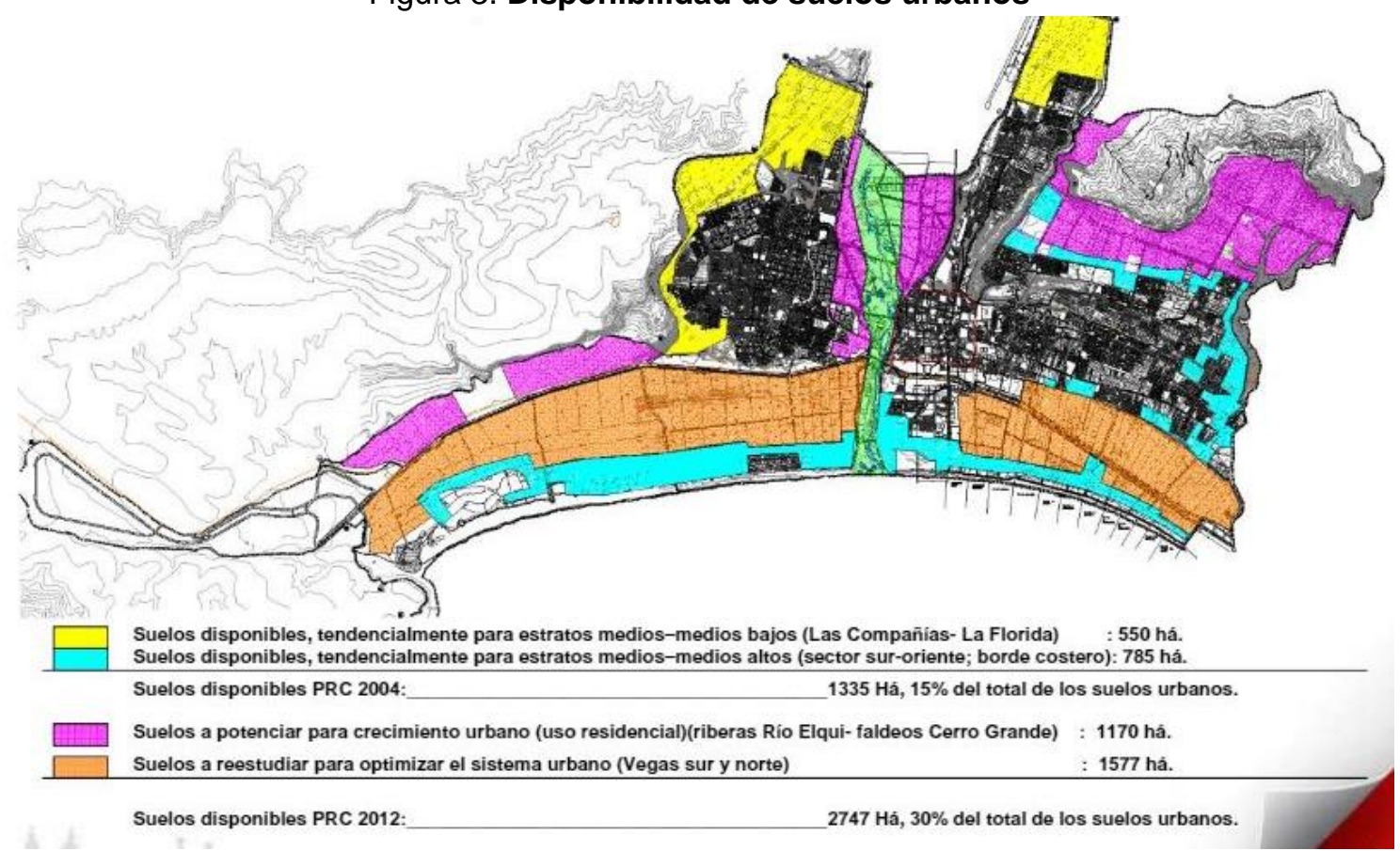

Fuente: Plan de regulador de La Serena

Por otro lado, el mercado privado de viviendas, se presenta en dos elementos de fuerza, uno que da respuesta a la constante migración estival como ciudad turística y un segundo que es la deslocalización de las clases medias y altas a zonas más periféricas de la conurbación, Asimismo, se debe hacer hincapié en este fenómeno, desde la perspectiva del mercado inmobiliario privado, como, asimismo, en el mercado de suelos agrícolas que se transforman en urbanos al corto o mediano plazo.

En ese sentido, se ha constatado una oferta de edificios ubicada en zona costera y con una compactación importante, aprovechando la primera y segunda línea de mar, en conjunto con edificaciones en extensión que se emplazan en la periferia. (Figura 4)

\section{Figura 4. Aviso publicitario}
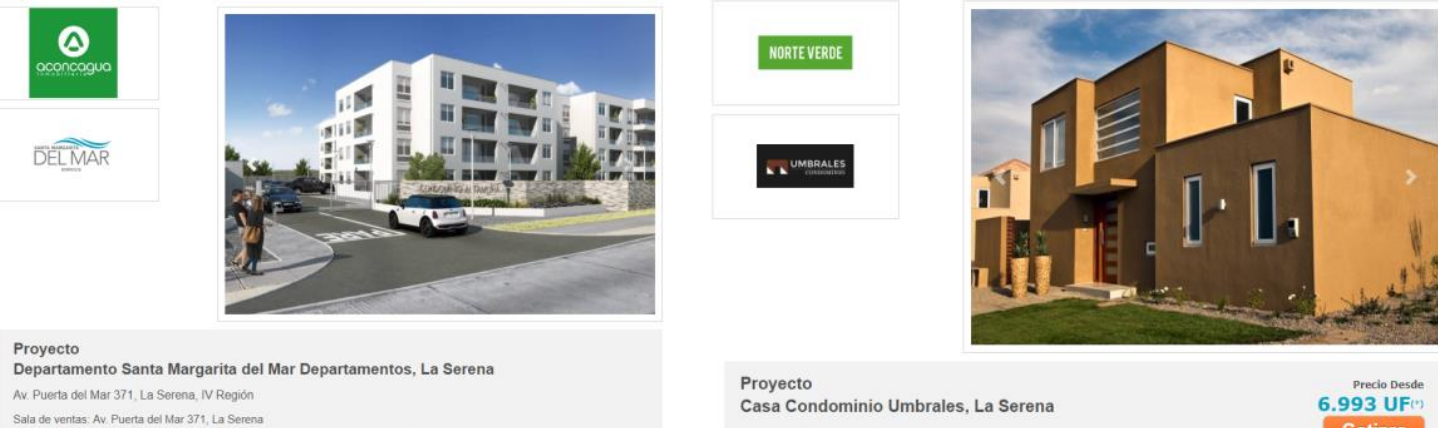
Sala de vertas Av Puerta de Mar 371 . La Sereng

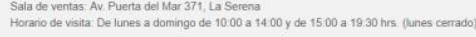

Fuente: Inmobiliaria Aconcagua. Disponible en: $\underline{\text { https://www.iaconcagua.com/proyectos?lugar=la+serena }}$

Citación: AGURRE N., C. et al. Patrones de crecimiento urbano en la metropolización de sistemas urbanos intermedios. El caso de la conurbación La Serena - Coquimbo. En: Libro de proceedings, CTV 2018. XII Congreso Internacional Ciudad y Territorio Virtual. "Ciudades y Territorios Inteligentes". UNCuyo, Mendoza, 5-7 septiembre 2018. Barcelona: CPSV, 2018, p. 77-96. 


\section{Metodología}

Esta investigación se desarrolla analizando datos secundarios y primarios, que establecen el primer producto del observatorio de la conurbación. Se tomó bases de datos disponibles por ley de transparencia del INE (www.ine.cl), además de levantamiento del área urbana desarrollada en el marco de la tesis doctoral de Alejandro Orellana, y que muestran el avance de la ciudad desde 1940 a la actualidad.

Con esta información se procedió a desarrollar un modelo integrado en una base de datos SIG, donde se cruzó el crecimiento urbano con los permisos de edificación geo localizados. Se procede a separar el análisis en dos grupos, primero un análisis descriptivo de los permisos y los crecimientos urbanos, para después pasar a la caracterizar los diferenciales del último crecimiento y proceder a calcular una puntuación factorial de los cada uno de ellos, en base a las tipologías edificatorias de cada uno.

\section{Figura 5. Metodología}

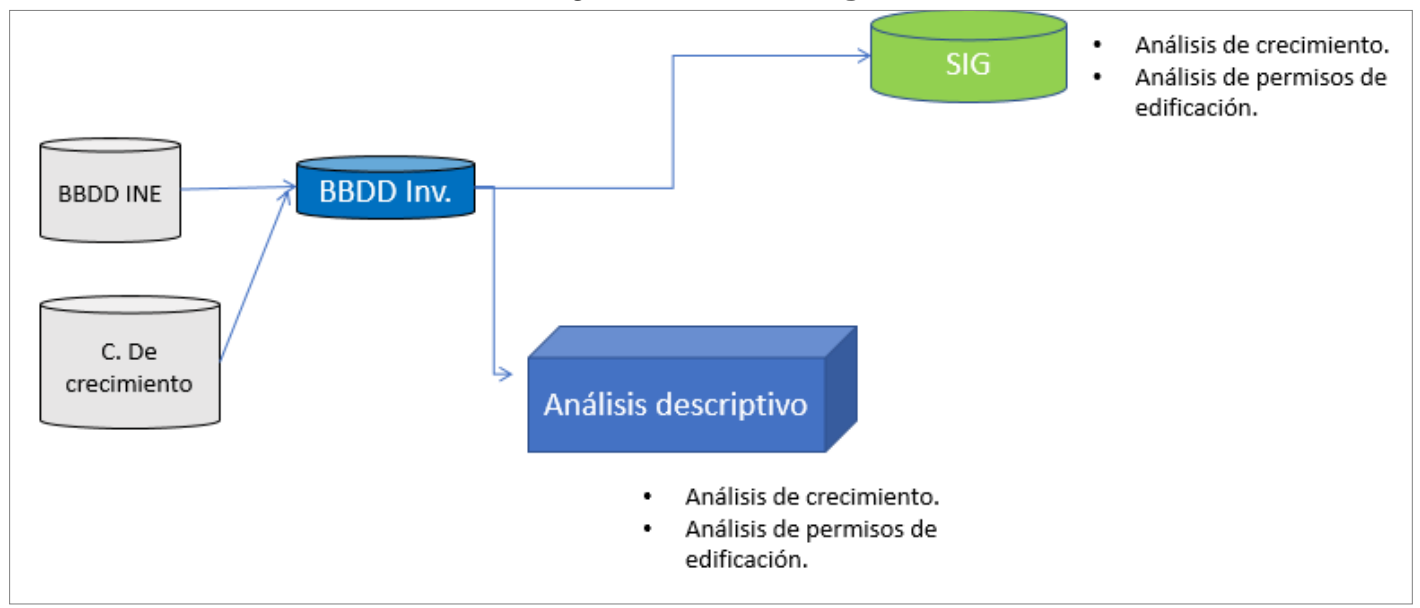

Fuente: Elaboración propia

\section{Resultados y discusión}

\subsection{Análisis descriptivo del crecimiento de la Conurbación}

La conurbación es la que presenta más crecimiento en la región, tanto por su condición de cabeza regional, como además un centro de servicios del norte del país. Como se observa en las figuras 6 y 7 , la Serena y Coquimbo aglutinan la mayor cantidad de viviendas y permisos en la región.

En la figura 8, se observa que los principales permisos de edificación, se entregan para viviendas en extensión, a lo largo del periodo. Sin embargo, las figura 9 nos muestra la situación de las comunas de La Serena y Coquimbo, donde se observa mayor diversidad de las alturas en La Serena, asociadas principalmente a lo restrictivo del plan regulador, lo que se corrobora en la figura 10 , donde se muestra el análisis de auto correlación espacial de los edificios considerando su altura. 
En este mismo análisis se muestra una de las primeras conclusiones. Existe un crecimiento fragmentado de la conurbación, donde el actor privado, utiliza los elementos normativos que más le convienen y, asimismo, presenta una baja relación con la concepción de ciudad. Esta suma de fragmentos, es sin duda una de las características de esta conurbación y una de sus condiciones basales de funcionamiento.

Figura 6. Permisos de edificación habitacionales en la Región de Coquimbo 2002-2015

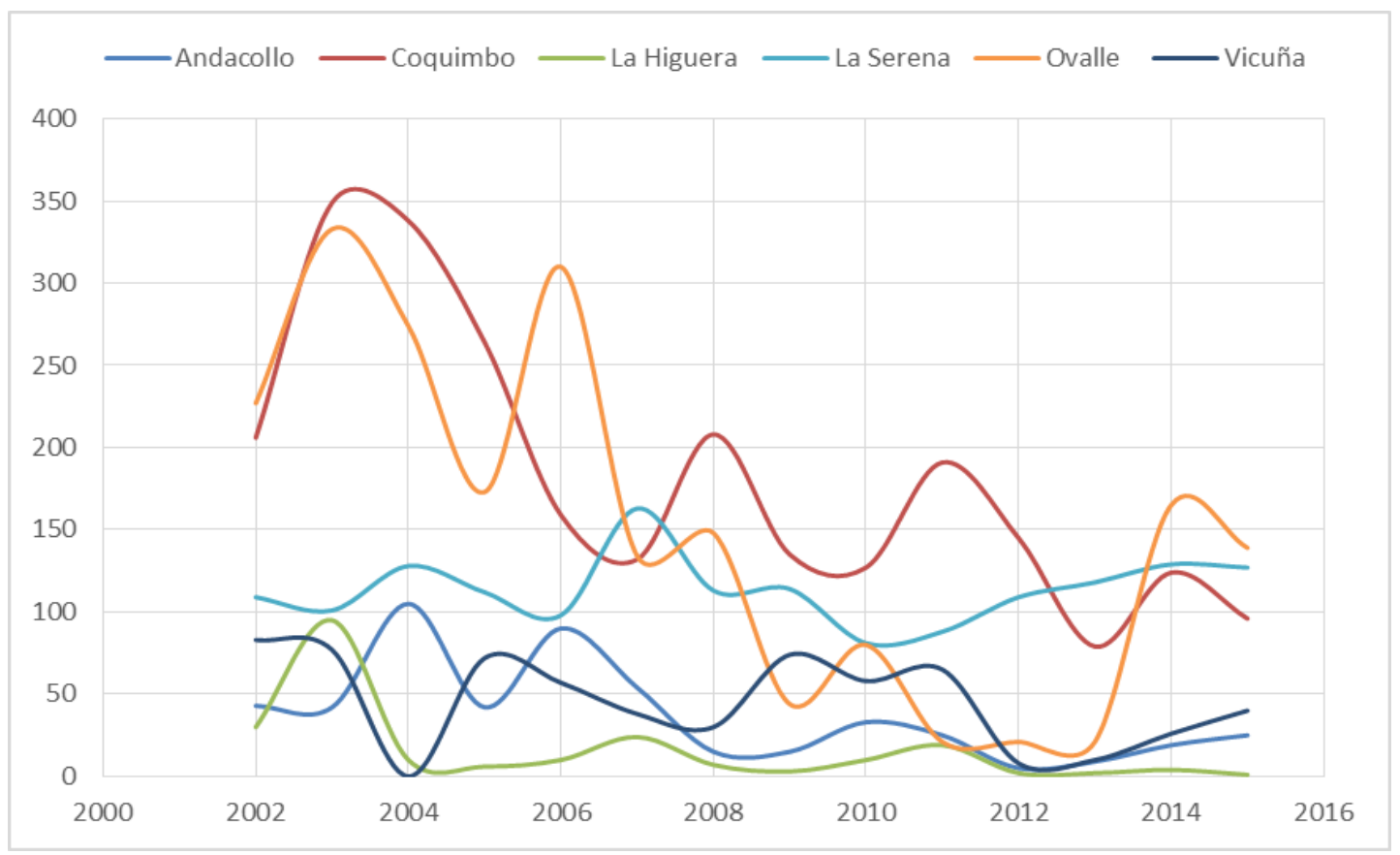

Fuente: Elaboración propia en base a los permisos de edificación de INE

Figura 7. Permisos de edificación habitacionales según cantidad de viviendas y comuna Región de Coquimbo 2002-2015

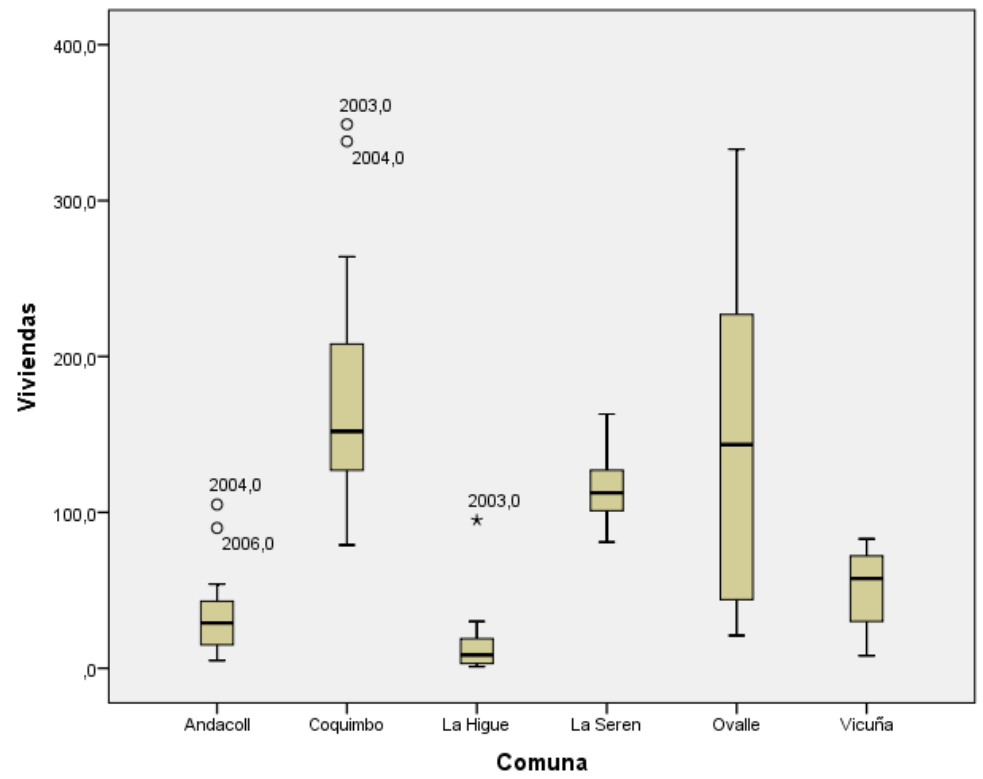

Fuente: Elaboración propia en base a los permisos de edificación de INE

Citación: AGURRE N., C. et al. Patrones de crecimiento urbano en la metropolización de sistemas urbanos intermedios. El caso de la conurbación La Serena - Coquimbo. En: Libro de proceedings, CTV 2018. XII Congreso Internacional Ciudad y Territorio Virtual. "Ciudades y Territorios Inteligentes". UNCuyo, Mendoza, 5-7 septiembre 2018. Barcelona: CPSV, 2018, p. 77-96. 
Figura 8. Permisos de edificación totales, según metros cuadrados y altura en pisos La Serena y Coquimbo 2002-2015

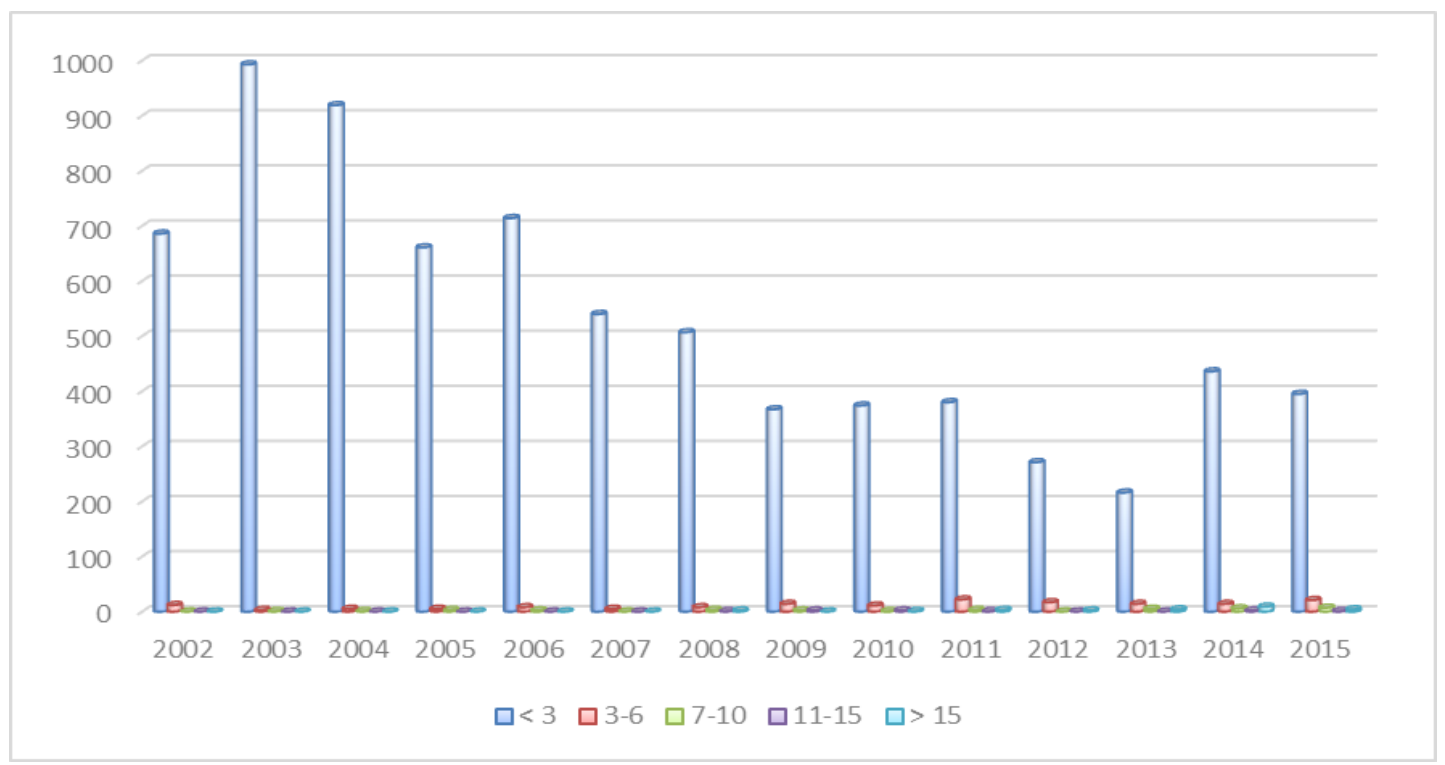

Fuente: Elaboración propia en base a los permisos de edificación de INE

Figura 9. Permisos de edificación totales, según cantidad de viviendas y altura en pisos La Serena y Coquimbo 201-2017

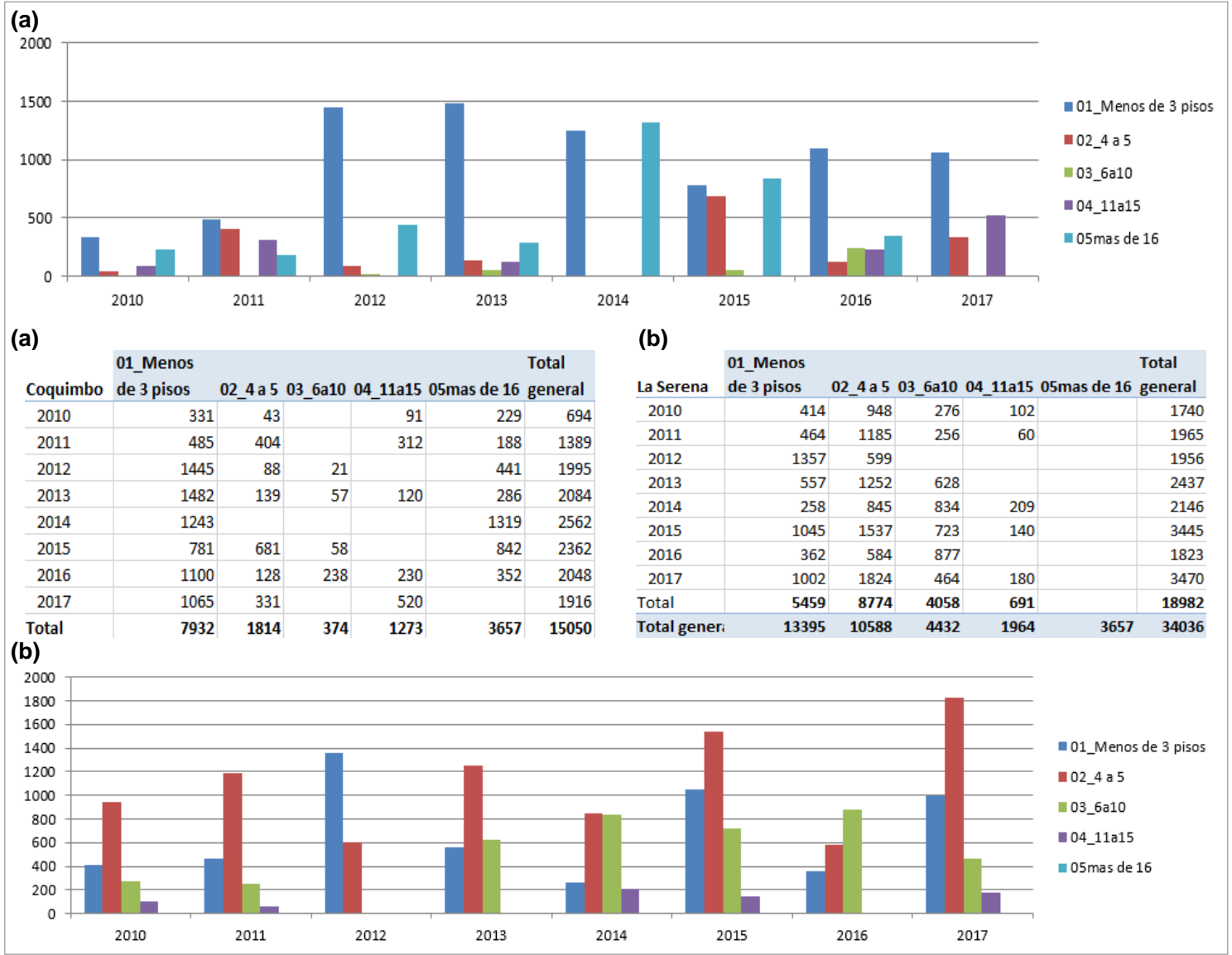

Fuente: Elaboración propia en base a los permisos de edificación de INE

Citación: AGURRE N., C. et al. Patrones de crecimiento urbano en la metropolización de sistemas urbanos intermedios. El caso de la conurbación La Serena - Coquimbo. En: Libro de proceedings, CTV 2018. XII Congreso Internacional Ciudad y Territorio Virtual. "Ciudades y Territorios Inteligentes". UNCuyo, Mendoza, 5-7 septiembre 2018. Barcelona: CPSV, 2018, p. 77-96. 
Figura 10. Análisis de auto correlación espacial LISA, por cantidad de viviendas y altura en pisos. La Serena y Coquimbo 2010-2017

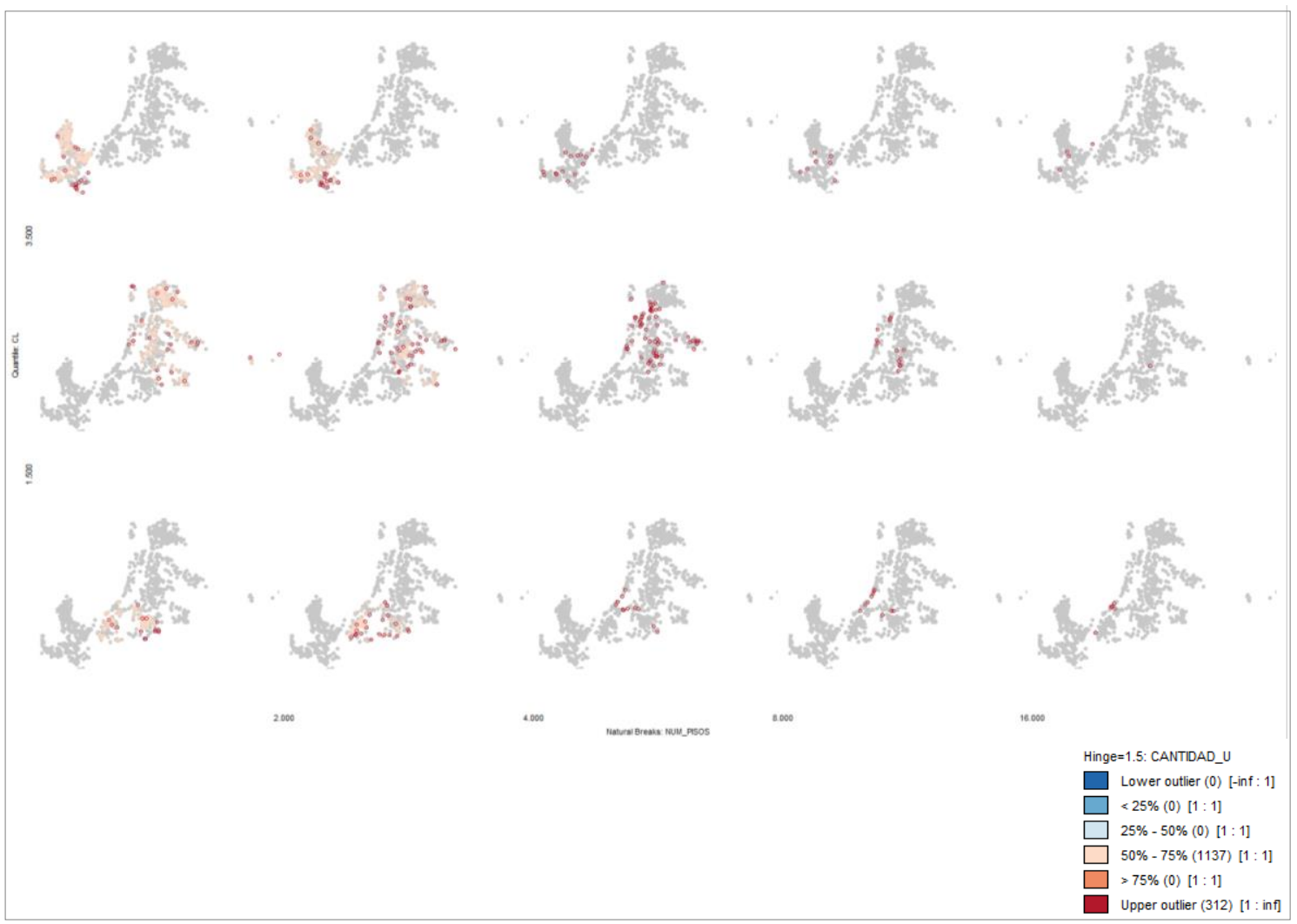

Fuente: Elaboración propia en base a los permisos de edificación de INE

Al calcular los índices de diversidad de Shannon (Aguirre, 2016), y localización con miras a establecer patrones de crecimiento de las diferentes comunas, encontramos que la comuna de La Serena cuenta con una mayor diversidad en los desarrollos de viviendas, contando con mayor número de edificaciones de las diferentes alturas, a excepción de las de más de 15 pisos, las cuales se ubican principalmente en la comuna de Coquimbo.

Aun así, ambas comunas han ganado diversidad en el periodo 2012-2015.

Figura 11. Diversidad e índice de localización de alturas de edificios. Total, periodo 2010-2017
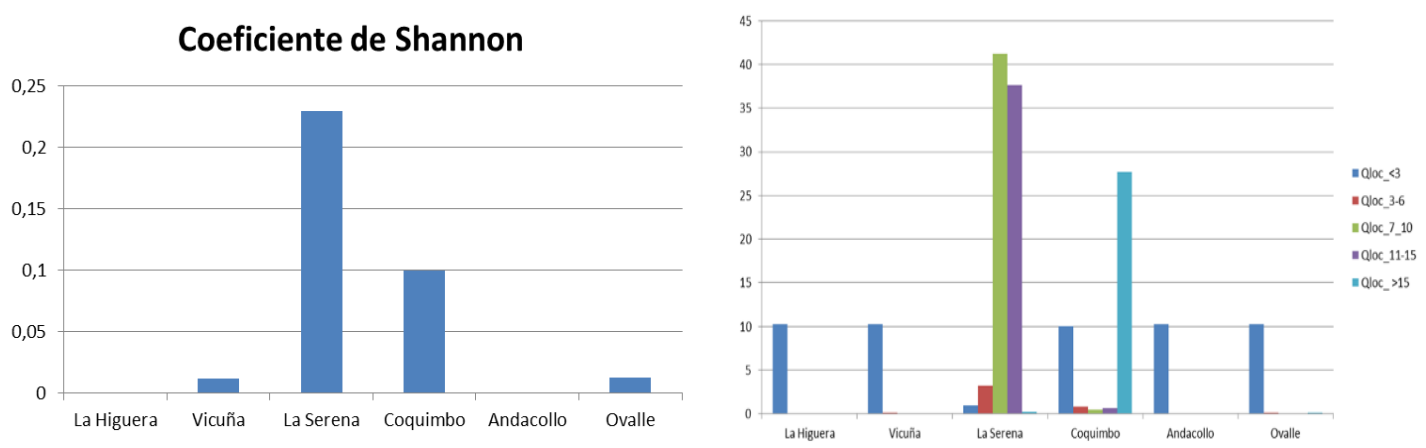

Fuente: Elaboración propia en base a permisos de edificación del INE

Citación: AGURRE N., C. et al. Patrones de crecimiento urbano en la metropolización de sistemas urbanos intermedios. El caso de la conurbación La Serena - Coquimbo. En: Libro de proceedings, CTV 2018. XII Congreso Internacional Ciudad y Territorio Virtual. "Ciudades y Territorios Inteligentes". UNCuyo, Mendoza, 5-7 septiembre 2018. Barcelona: CPSV, 2018, p. $77-96$ 
Figura 12. Evolución de las Diversidad de alturas de edificios

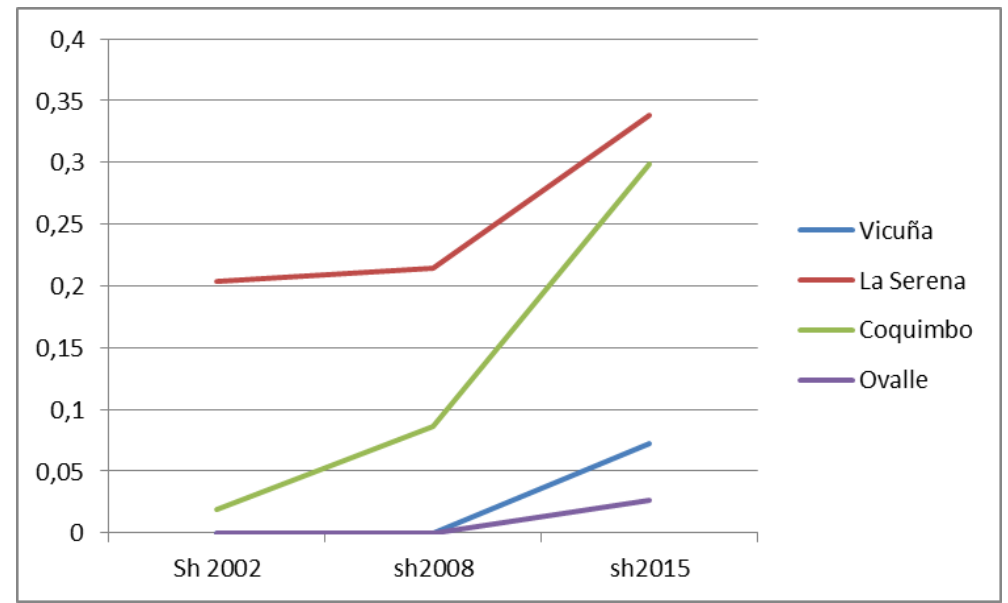

Fuente: Elaboración propia en base a permisos de edificación del INE

\subsection{Análisis Espacial del crecimiento de la conurbación}

El crecimiento urbano de la conurbación, desde los años 40 hasta el 2018, ha sido muy fragmentado, como se observa la conurbación presenta particularidades, como mantener 3 núcleos urbanos en crecimiento y que hasta el 2018 no logran formar un continuo. En el 2018, se le agregan dos nuevos fragmentos en la zona norte, como desarrollo turístico.

En ese sentido, algunos de los fragmentos identificados en el año 1952(año de implementación del plan Serena), se integran al continuo urbano central (La Serena), desde los años 70, ya que aparecen dentro de la marcha central desde el año 1982.

En ese sentido el periodo 2012 al 2018, es el que presenta mayor consolidación de las manchas urbanas, concentrándolas en 5 unidades. Una central de la Serena que desborda sus límites conocidos, adentrándose al valle, por la florida y por la parte este de la comuna de Coquimbo, La comuna de Coquimbo que se concentra en el puerto ampliándose hacia el sur, la zona de las compañías, que crece en forma de extensión, y dos zonas turísticas, una cercana a la Serena, en su zona litoral norte, y la otra en la periferia norte, al final de la bahía de Coquimbo. (Figuras 13 a 15)

Al analizar los patrones de ubicación de los permisos de edificación, se desarrollaron varios análisis, el primero se muestra en a la figura 16, en el cual se calcula las correlaciones espaciales significativas, de los permisos de edificación, considerando una organización de vecino más próximo y asimismo la variable de cantidad de unidades según número de pisos, como principal.

Tal como se observa, existen siete zonas de alta significancia, los núcleos urbanos identificados anteriormente y los crecimientos o desbordes a estos. Es importante recalcar que esta significancia permite establecer algunos elementos de aglomeración en el uso del territorio con una tipología edificatoria en especial, por sobre otras. En ese sentido, se observa que los elementos de este crecimiento también son fragmentados $y$, asimismo, se plantean en extensión o altura definiendo un crecimiento errático o no ordenado.

Citación: AGURRE N., C. et al. Patrones de crecimiento urbano en la metropolización de sistemas urbanos intermedios. El caso de la conurbación La Serena - Coquimbo. En: Libro de proceedings, CTV 2018. XII Congreso Internacional Ciudad y Territorio Virtual. "Ciudades y Territorios Inteligentes". UNCuyo, Mendoza, 5-7 septiembre 2018. Barcelona: CPSV, 2018, p. 77-96. 
Figura 13. Mancha urbana de la conurbación La Serena Coquimbo, en área de suelo artificializado por periodo 1940-1992

1940

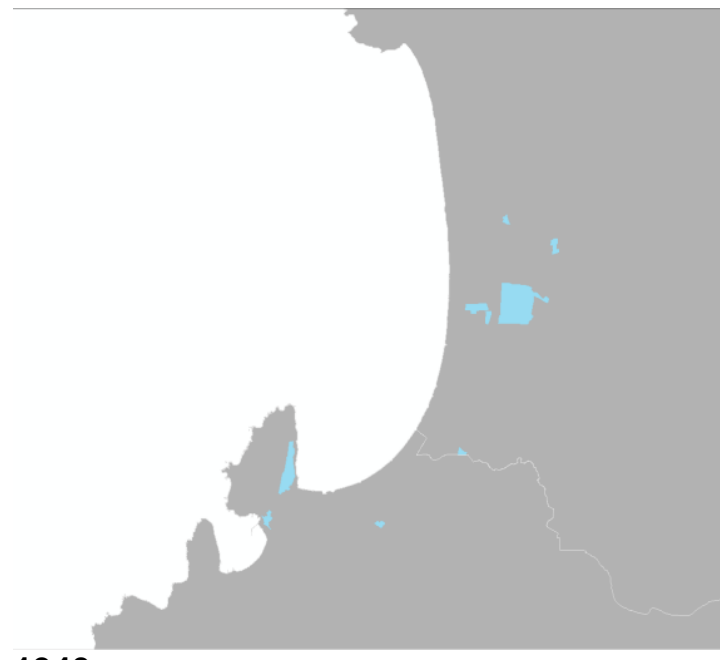

1960
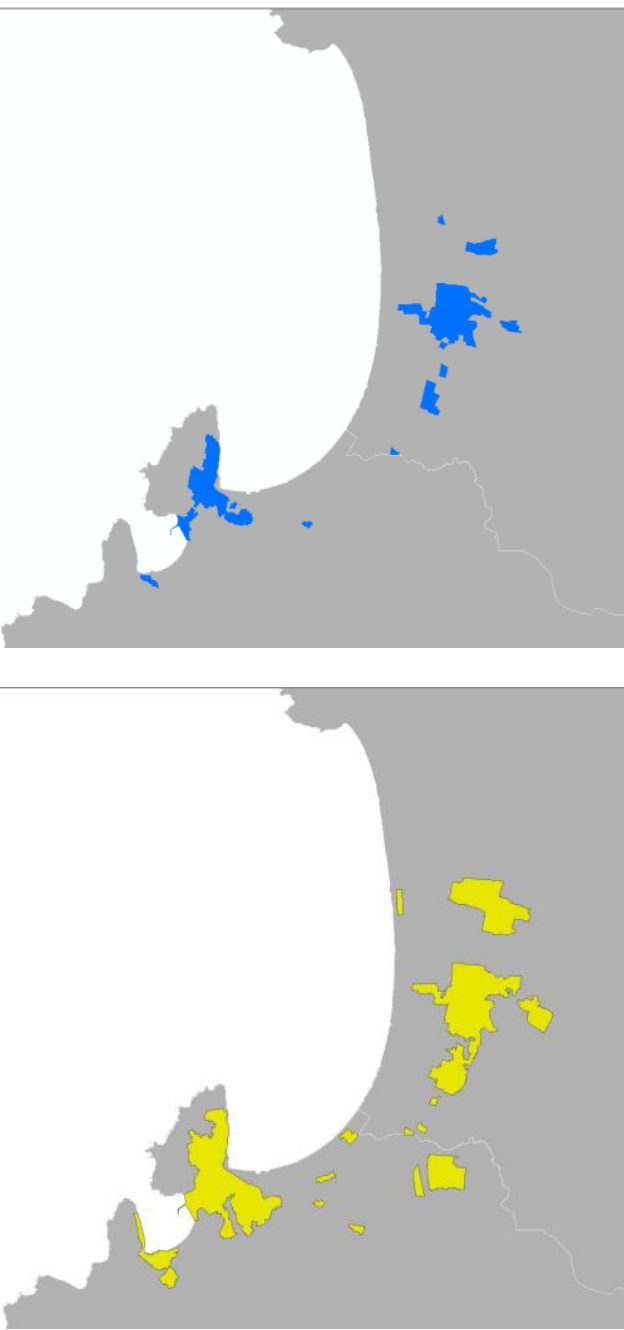

1982
1952
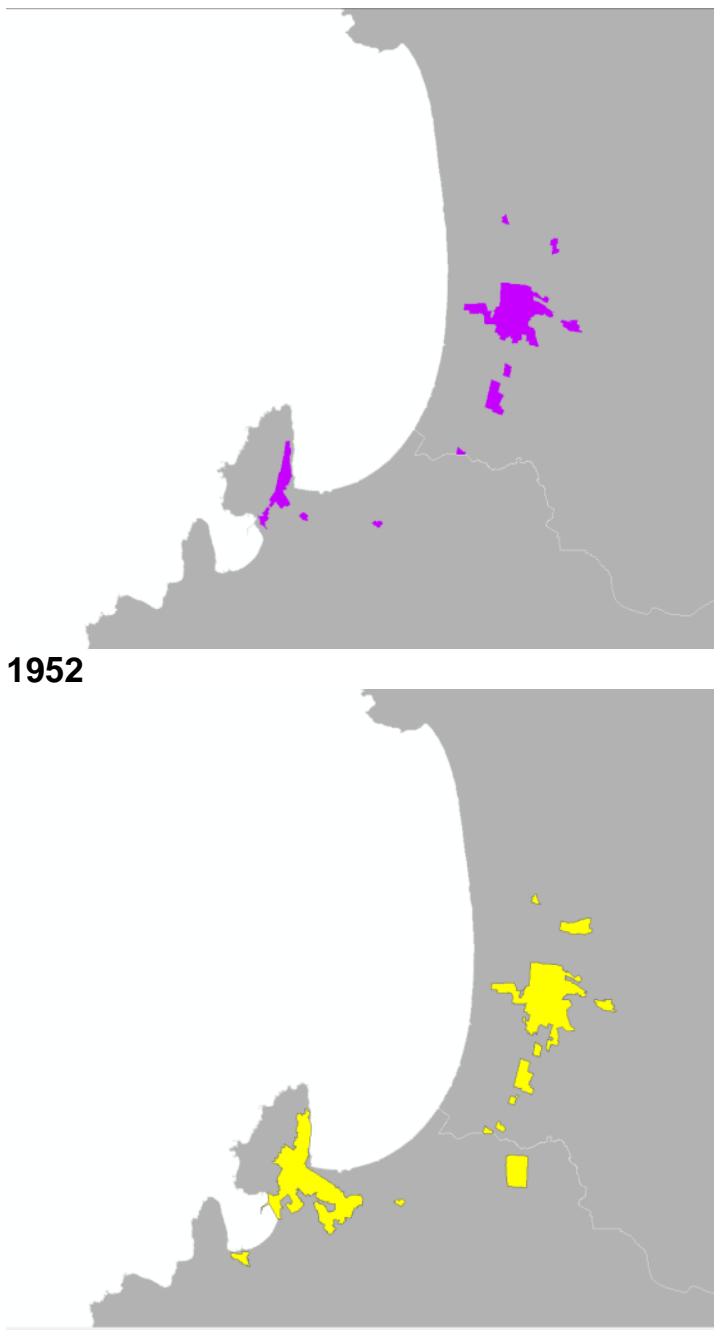

1970

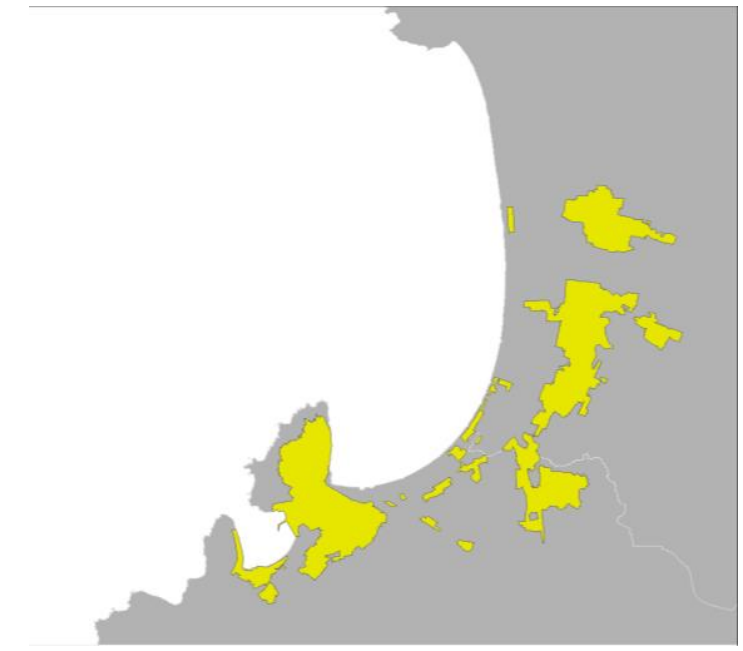

1992

Nota: continúa en página siguiente.

Citación: AGURRE N., C. et al. Patrones de crecimiento urbano en la metropolización de sistemas urbanos intermedios. El caso de la conurbación La Serena - Coquimbo. En: Libro de proceedings, CTV 2018. XII Congreso Internacional Ciudad y Territorio Virtual. "Ciudades y Territorios Inteligentes". UNCuyo, Mendoza, 5-7 septiembre 2018. Barcelona: CPSV, 2018, p. 77-96. 

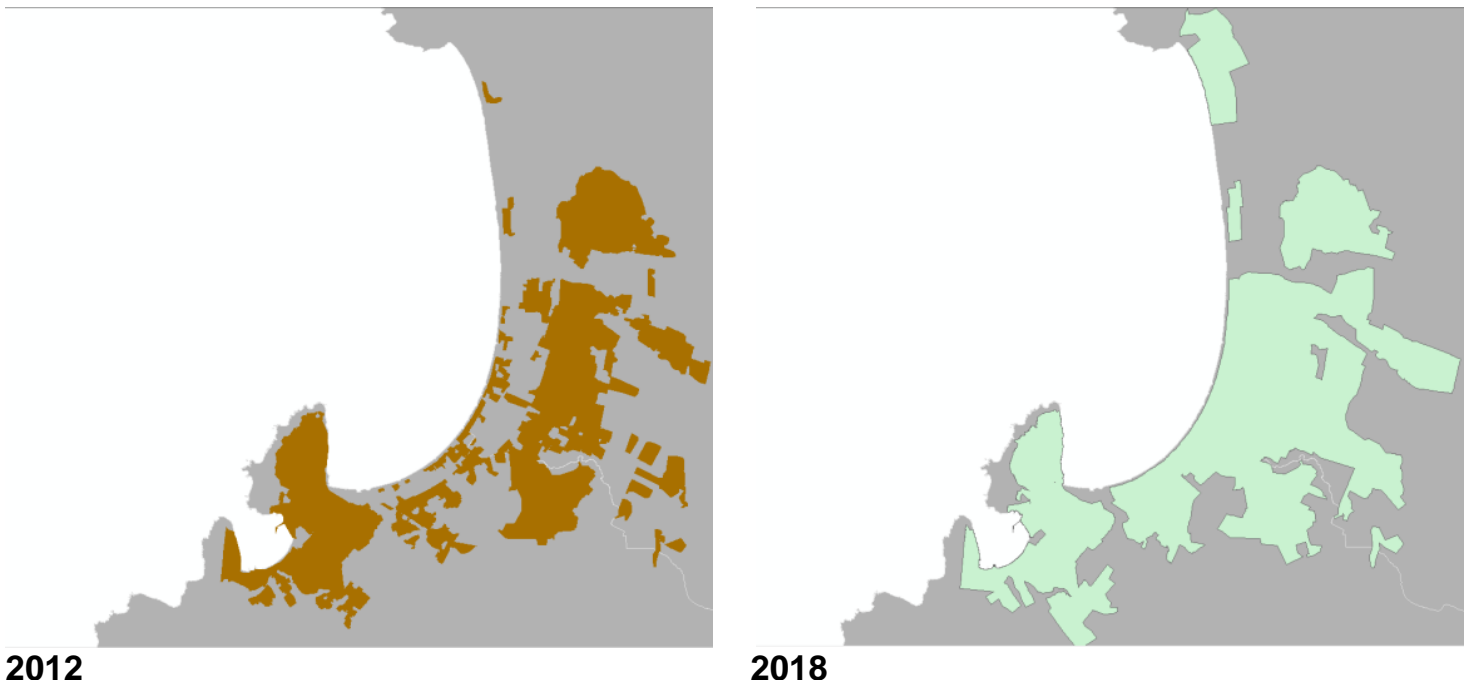

Fuente: Elaboración propia

Figura 14. Mancha urbana de la conurbación La Serena Coquimbo, en área de suelo artificializado por periodo 1940-2018
$\square$ \ancha_1940
-
$\boxminus \square$ Mancha_1952
(1)
$\boxminus \square$ Mancha_1960
$\square$
$\boxminus \square$ Mancha_1970
$\square$
$\boxminus \square$ Mancha_1982
$\square$
$\boxminus \square$ Mancha_1992
$\square$
$\boxminus \square$ Mancha_2002
$\square$
曰 $\square$ Mancha_2012
미
$\boxminus \square$ Mancha_2018
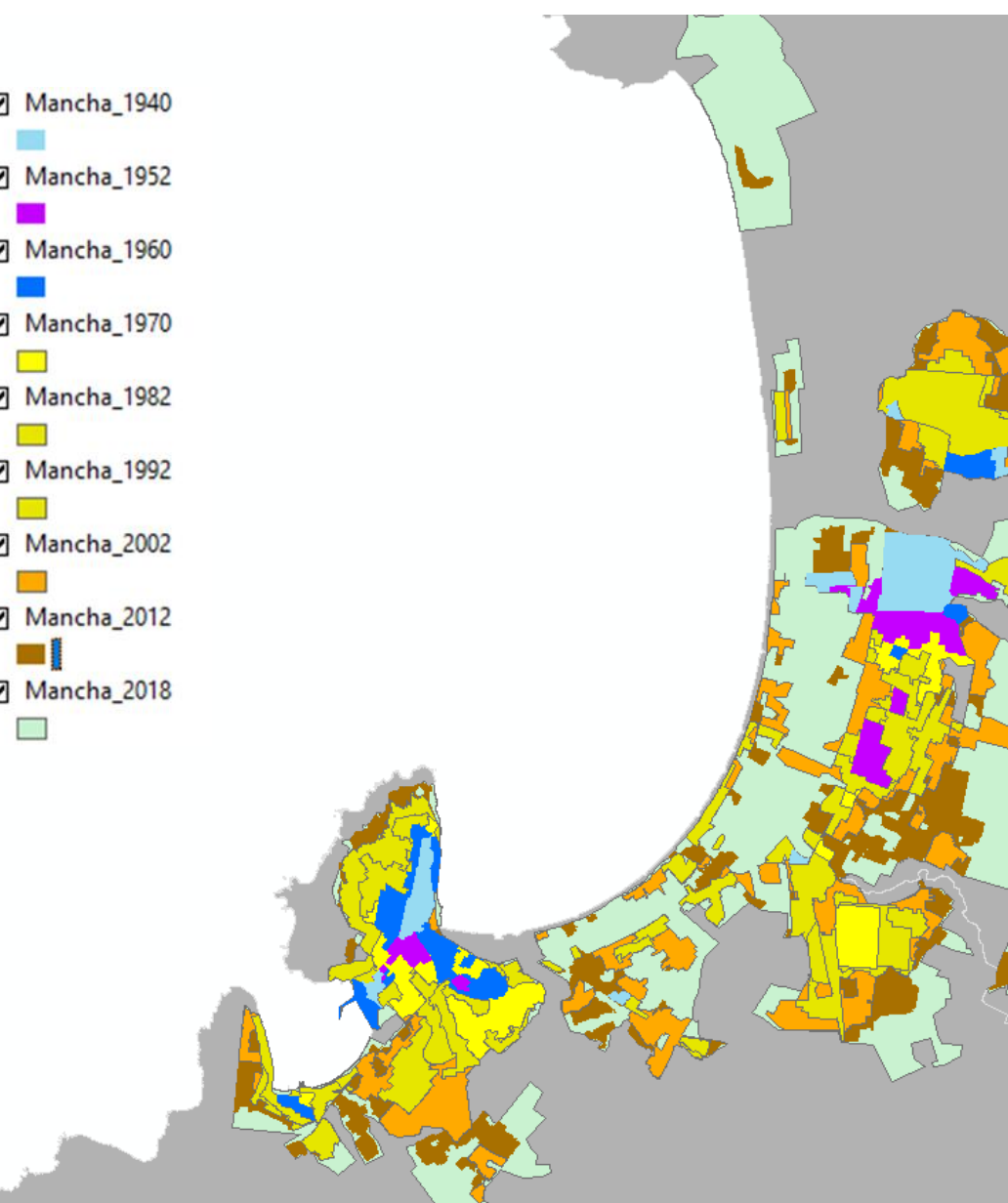
Figura 15. Mancha urbana de la conurbación La Serena Coquimbo, en área de suelo artificializado por periodo 2012-2018 con los permisos de edificación geolocalizados

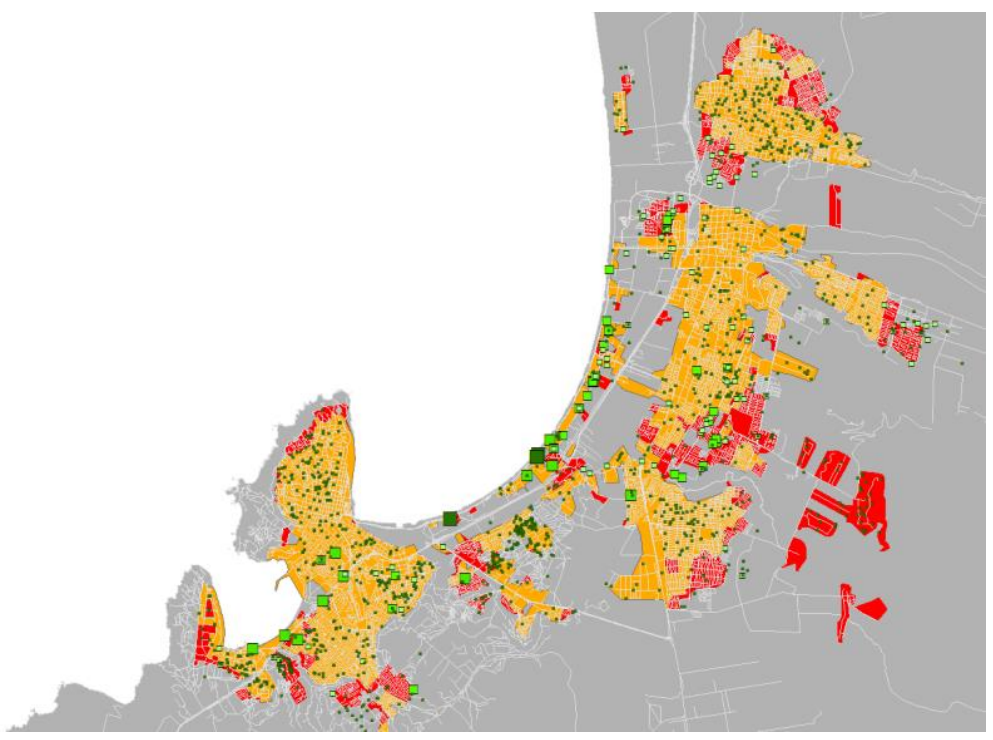

Fuente: Elaboración propia

Figura 16. Auto correlación espacial de los permisos de edificación geolocalizados 2012-2017

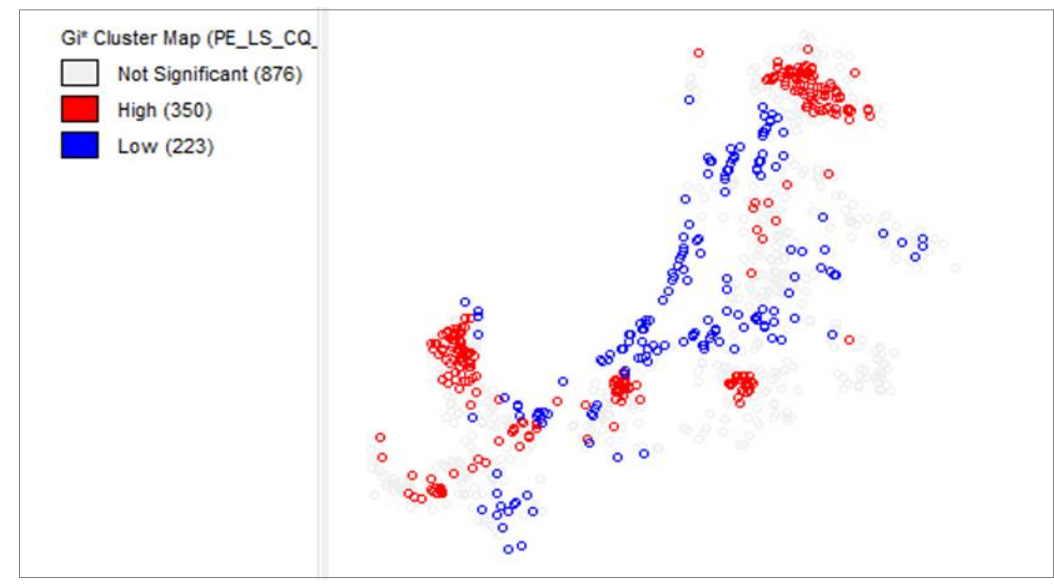

Fuente: Elaboración propia

Si analizamos los permisos y la correlación de la mancha urbana, podemos identificar diferentes secciones o sectores (Figura 17 y 18), donde podemos establecer una caracterización inicial por la cantidad de viviendas y superficies aprobadas, según tipología edificatoria, más de 3 pisos y plurifamiliar, en densidad, y menos de tres pisos y unifamiliar en extensión.

Por otra parte, se realiza un análisis factorial de los valores de cada una de las secciones, donde se identifican 2 dimensiones latentes, una que establece el crecimiento por Densidad, el PC1 y el por extensión en el PC2. Las figuras 19 a 21, presentan los valores de la dimensión PC1, en dialogo con las variables PC2, (crecimiento por extensión), la cantidad de unidades en densidad y en extensión, según corresponda.

Citación: AGURRE N., C. et al. Patrones de crecimiento urbano en la metropolización de sistemas urbanos intermedios. El caso de la conurbación La Serena - Coquimbo. En: Libro de proceedings, CTV 2018. XII Congreso Internacional Ciudad y Territorio Virtual. "Ciudades y Territorios Inteligentes". UNCuyo, Mendoza, 5-7 septiembre 2018. Barcelona: CPSV, 2018, p. 77-96. 
En este análisis se caracterizan las secciones de crecimiento en extensión y densidad, observando secciones muy definidas y fragmentadas, propias de un proceso de crecimiento errático y son relación con los elementos funcionales.

Si bien la densificación se realiza en las zonas de desborde de los núcleos iniciales, esta tampoco guarda relación con el acceso a los bienes públicos propios de la ciudad intermedia, como servicios y trabajo. Asimismo, esta incoherencia entre el funcionamiento de la ciudad y su planificación explican los problemas identificados en el primer acápite, dado que estos fragmentos están lejos de ser auto contenidos, y por ende cuentan con movilidad diaria obligada, tanto por trabajo y educación, como por acceso a comercio y ocio.

\section{Figura 17. Puntuación Factorial de cada sector}

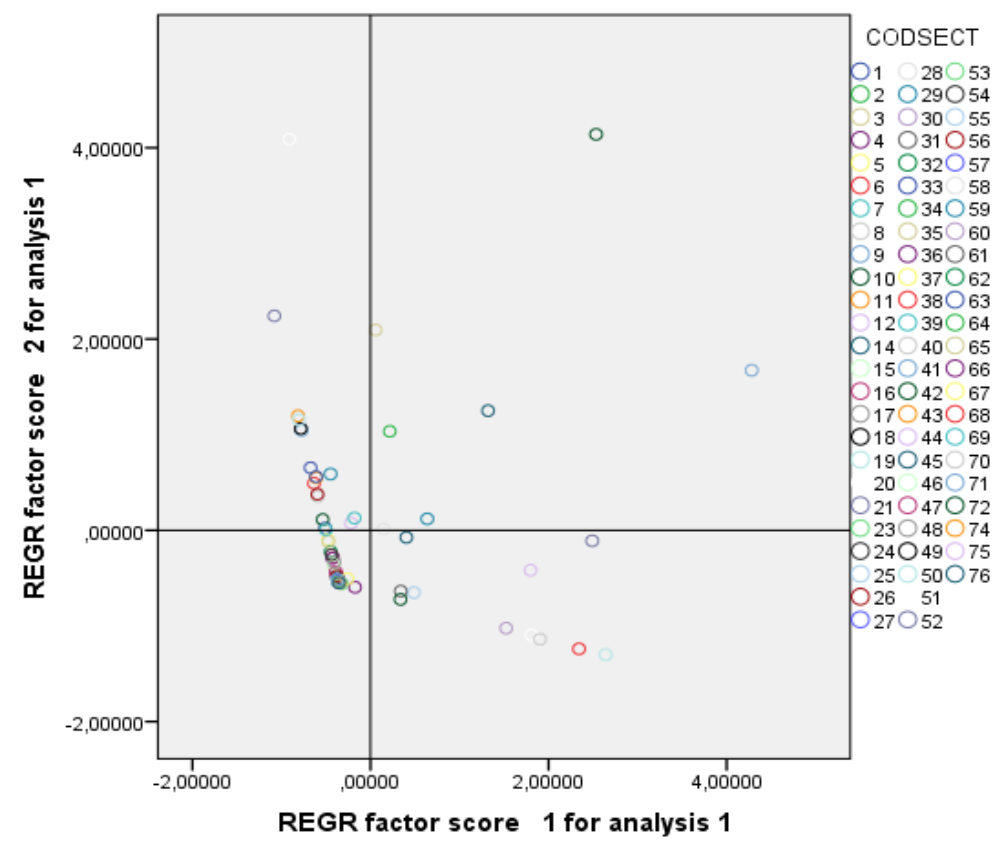

Fuente: Elaboración propia

Figura 18. Cantidad de viviendas
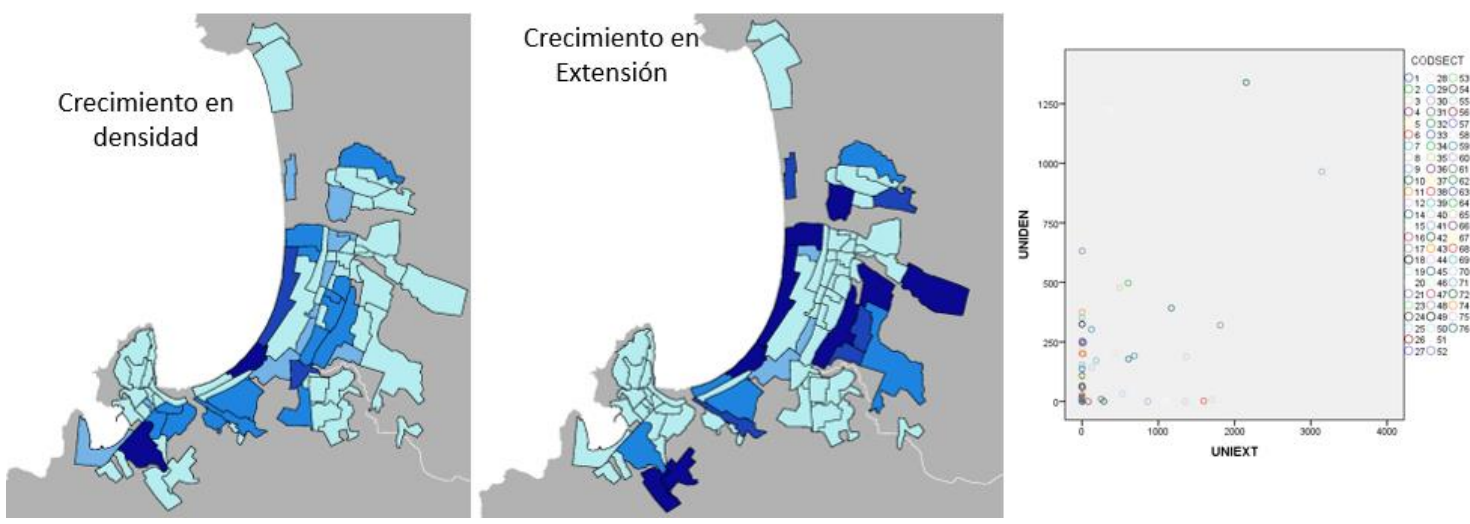

Fuente: Elaboración propia

Citación: AGURRE N., C. et al. Patrones de crecimiento urbano en la metropolización de sistemas urbanos intermedios. El caso de la conurbación La Serena - Coquimbo. En: Libro de proceedings, CTV 2018. XII Congreso Internacional Ciudad y Territorio Virtual. "Ciudades y Territorios Inteligentes". UNCuyo, Mendoza, 5-7 septiembre 2018. Barcelona: CPSV, 2018, p. 77-96. 
Figura 19. Superficies aprobadas
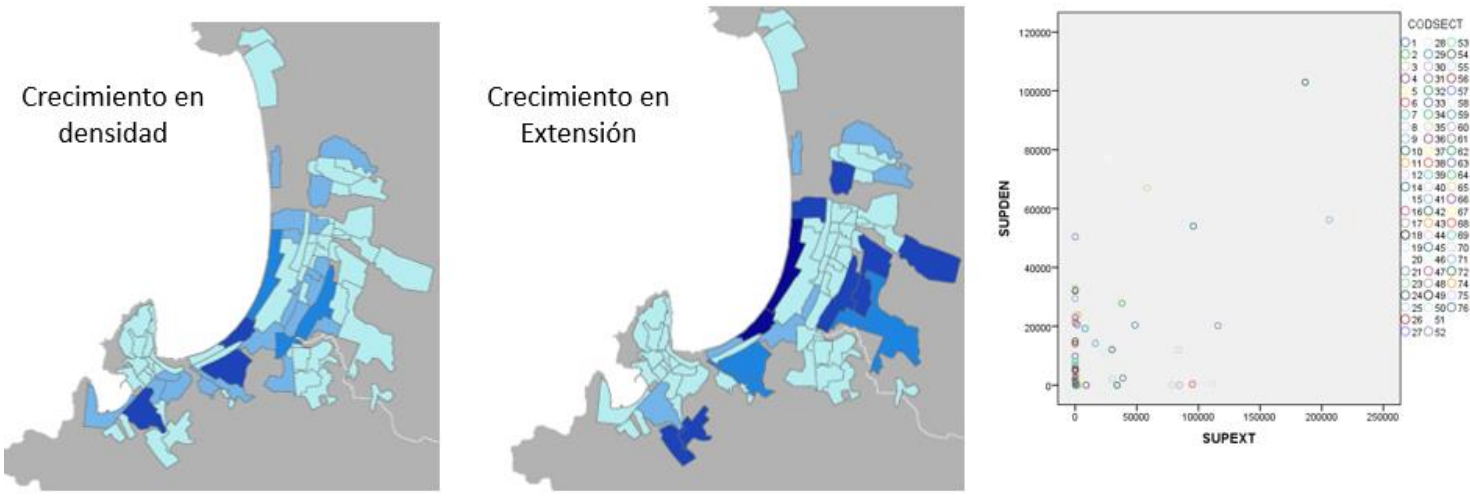

Fuente: Elaboración propia

Figura 20. Factor de dimensión en extensión (PC1) contra cantidad de unidades de vivienda en densidad

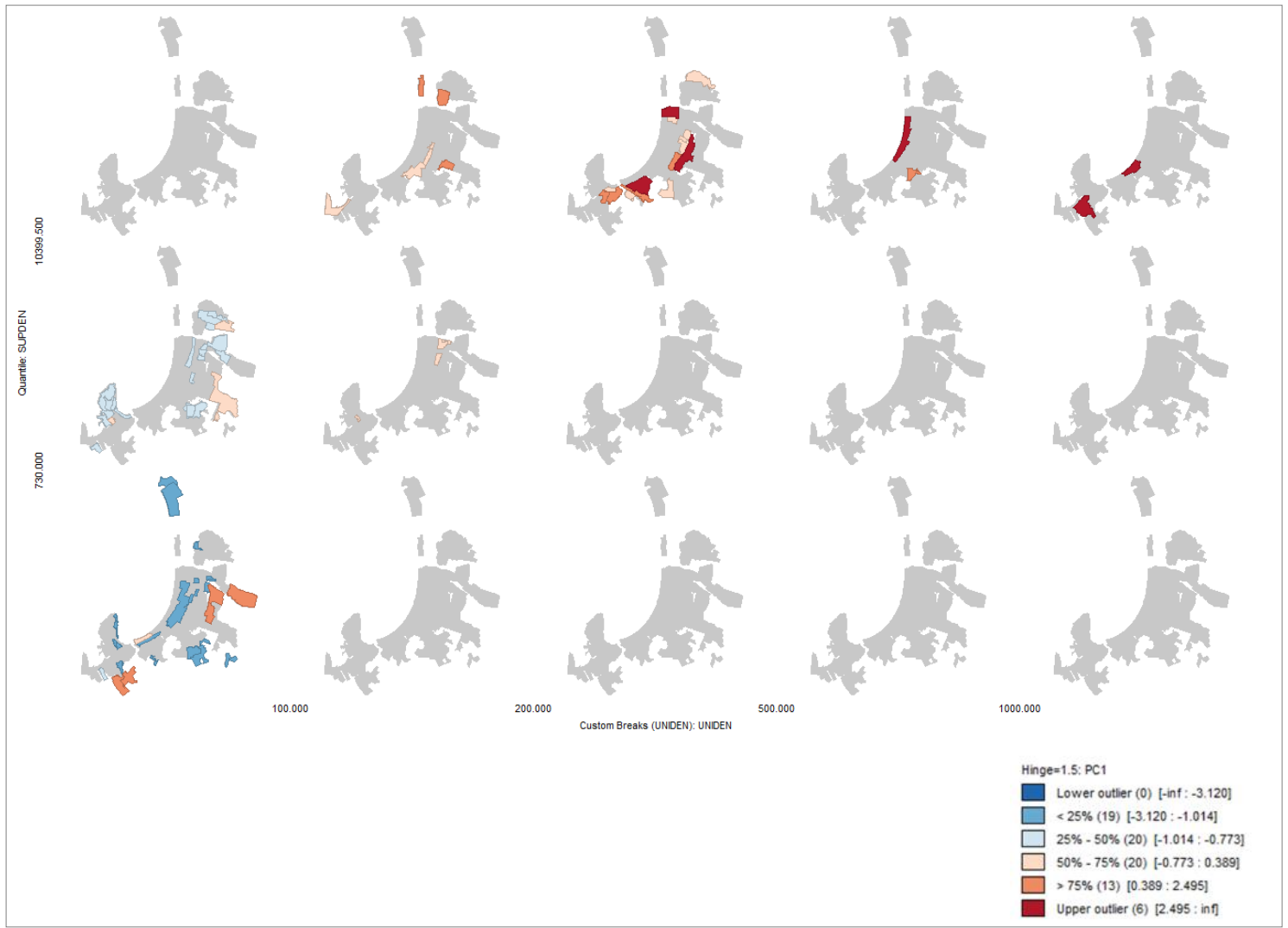

\section{Conclusiones}

El desarrollo de la conurbación la Serena Coquimbo se caracteriza por un mercado liberalizado de suelo y vivienda, propios de la transformación capitalista y la consolidación de un modelo neoliberal de ciudad. Esto ha permitido que la conurbación crezca de forma paradojal, donde se produce un proceso de metropolización en base a fragmentos urbanos, claramente identificados en el artículo y que se expande por colmatación, fenómeno que hemos

Citación: AGURRE N., C. et al. Patrones de crecimiento urbano en la metropolización de sistemas urbanos intermedios. El caso de la conurbación La Serena - Coquimbo. En: Libro de proceedings, CTV 2018. XII Congreso Internacional Ciudad y Territorio Virtual. "Ciudades y Territorios Inteligentes". UNCuyo, Mendoza, 5-7 septiembre 2018. Barcelona: CPSV, 2018, p. 77-96. 
denominado el puzzle, debido a que va llenando espacios vacíos intermedios después de completar un perímetro, pero a la ves genera otros nuevos fragmentos.

Si correlacionamos esto con los modelos de ciudades y su gobernanza, existe una necesidad de poner en la mirada en los sistemas urbanos intermedios, a escala intermedia, donde existen procesos de metropolización que difieren de las metrópolis tradicionales, y por ende concentrar las políticas públicas en la operación de la ciudad intermedia, más que el diagnostico o planificación.

\section{Bibliografía}

AGUIRRE N., C. y BURBOA G., Análisis de la renovación urbana de la comuna de Santiago 1998-2005. En: Revista de la Construcción, 2006, 5 (1): 81-89.

AGUIRRE N., C. Analysis of chilean metropolitan areas, the case of Santiago, and Concepcion: location patterns as building licences 2002-2010. En: Virtual City and Territory. "Back to the Sense of the City: International Monograph Book". Barcelona: Centre de Política de Sòl i Valoracions, 2016, p. 777-797.

CENTRO DE DESARROLlO URBANO SUSTENTABLE, Pontificia Universidad Catolica de Chile. (s.f.). Sintesis principales resultados Conversatorios Urbanos. Coquimbo, La Serena.

DAHER HECHEM, A. (2015). Metropolización en la región de mayor crecimiento de Chile, Coquimbo. En: AUS, 19, 45-50. [En línea] Disponible en: http://ausrevista.cl/index.php/es/nactual/26-revista-n-19/204-metropolizacio-n-en-la-regio-n-de-mayor-crecimiento-de-chile-coquimbo

FIERRO PAGE, M. T. Primer ensayo urbanístico regional, modernidad en La Serena, 1946 1952. En: REVISTA DE URBANISMO, 2015 (32): 32-53. [En línea] DOI: http://dx.doi.org/10.5354/0717-5051.2015.36556

GOBIERNO REGIONAL DE COQUIMBO. (s.f.). Estrategia Regional de desarrollo de Coquimbo, 2020.

HIDALGO, R., DE MATTOS, C. \& ARENAS, F. (Eds.) Chile: del país urbano al país metropolitano. Pontificia Universidad Catpolica de Chile. 2013. [En línea] Disponible en: http://geografia.uc.cl/Coleccion-en-linea/chile-del-pais-urbano-al-pais-metropolitano-en-linea.html? $\underline{\text { server }=1}$

HIDALGO, R.; TRUMPER, R., \& BORSDORF, A. Transformaciones urbanas y procesos territoriales. Lectura del nuevo dibujo de la ciudad latinoamericano. Serie geolbros. 2015.

Maturana M., F., \& Rojas B., A. (2014). Ciudades intemedias en Chile, Territorios Olvidados.

ORELLANA MC BRITE, A.; DIAZ ZAMORA, M. \& FIERRO PAGE, M. T. De Ciudad meditarranea a metrópolis costera, el caso de Gran Serena. En: Urbano, 19 (34): 30-43. 2016.

TORRENT, H. Patrimonio territorial y arquitectónico: El Plan Serena. En: Urbano, 2004, 7 (10): 93-99. [En línea] Disponible en: http://revistas.ubiobio.cl/index.php/RU/article/view/532

Citación: AGURRE N., C. et al. Patrones de crecimiento urbano en la metropolización de sistemas urbanos intermedios. El caso de la conurbación La Serena - Coquimbo. En: Libro de proceedings, CTV 2018. XII Congreso Internacional Ciudad y Territorio Virtual. "Ciudades y Territorios Inteligentes". UNCuyo, Mendoza, 5-7 septiembre 2018. Barcelona: CPSV, 2018, p. 77-96. 